\title{
Evaluation of Flow Mixing in an ARID-HV Algal Raceway using Statistics of Temporal and Spatial Distribution of Fluid Particles
}

\author{
Ben $\mathrm{Xu}^{\mathrm{a}}$ ，Peiwen $\mathrm{Li}^{\mathrm{a}}$ ，Peter Waller ${ }^{\mathrm{b}}$, Michael Huesemann ${ }^{\mathrm{c}}$ \\ a. Department of Aerospace and Mechanical Engineering, University of Arizona, Tucson, AZ 85721, USA \\ b. Department of Agricultural and Biosystems Engineering, University of Arizona, Tucson, AZ 85721, USA \\ c. Pacific Northwest National Laboratory, Department of Energy, Sequim, Washington 98382, USA \\ *Corresponding author. Tel.: 520-626-7789; Fax: 520-621-8191; \\ Email address: peiwen@email.arizona.edu (Peiwen Li)
}

\begin{abstract}
This paper analyzes and evaluates the flow mixing in an open channel algal raceway for biofuel production. The flow mixing governs the frequency of how algae cells are exposed to sunlight, due to the fluid movement between the surface and the bottom of the algal raceway, thereby affecting algal growth rate. In this work, we investigated the flow mixing performance in a table-sized model of the High Velocity Algae Raceway Integrated Design (ARID-HV). Various geometries of the raceway channels and dams were considered in both the CFD analysis and experimental flow visualization. In the CFD simulation, the pathlines of fluid particles were analyzed to obtain the distribution of the number of times that particles passed across a critical water depth, Dc, defined as a cycle count. In addition, the distribution of the time period fraction that the fluid particles stayed in the zones above and below Dc was recorded. Such information was used to evaluate the flow mixing in the raceway. The CFD evaluation of the flow mixing was validated using experimental flow visualization, which showed a good qualitative agreement with the numerical results. In conclusion, this CFD-based evaluation methodology is recommended for flow field optimization for open channel algal raceways, as well as for other engineering applications in which flow mixing is an important concern.
\end{abstract}

Keywords: Algae raceway; CFD; Flow mixing evaluation; Fluid particles; Statistics; Temporal and spatial distributions.

\section{Introduction}


As one of the environmentally benign energy technologies (Kromer et al., 2010), growing algae for biofuel has been receiving more and more attention in recent years. Algae consumes $\mathrm{CO}_{2}$ and thus recycles $\mathrm{CO}_{2}$ from the atmosphere to form new fuel, which is widely viewed as one of the most effective ways to reduce greenhouse gases in the global atmosphere (Sun et al, 2011; Kucukvar et al., 2011).

Algae growth is influenced by many factors, including water temperature, concentrations of nutrients, and $\mathrm{CO}_{2}$, as well as the exposure of algae cells to periods of sunlight and darkness (James and Boriah, 2010; Marshall et al., 2010; Beal et al., 2012; Wang et al., 2008; Merchuk etal., 2011). Light exposure is closely related to the depth of water and fluid flow structures due to a raceway's flow field design (Foy et al., 1976). The average light/dark cycles experienced by cells depend not only on the actual depth of the reactor but also on the incident light intensity.

Algae photosynthesis in sunlight generates energy in the form of sugars and produces intermediate products, which are used for carbon dioxide fixation and synthesis of biomass. When algal cells are transferred from light (on surface) to dark (deep at bottom), photosynthesis can only continue for a short period of time in the dark. This implies that the dark reaction can be the rate-limiting step in the overall process. Algae cells continue to grow in the dark zones, until all the energy/intermediate products stored during their stay in the light zone are used up. After that, growth stops and endogenous respiration may take place, leading to a decrease in biomass concentration in the algal culture. Lee and Pirt (1981) found that the growth rate of microalgae cells is reduced if algae cells remain in the dark zones for too long. On the other hand, Merchuk et al. (1998) suggested that a short duration in darkness is necessary for cells to recover from photoinhibition.

The time period during which algal cells stay in darkness (at bottom zone) or in sunlight (at top zone) is related to cell movement in the flow field. Ogbinna et al. (1995) conducted experiments to study the effects of cell movement on algal productivity for two different kinds of algae, by randomly mixing the surface and the bottom of photobioreactors. They drew several conclusions: (1) at low cell concentration, movement of cells between surface and bottom zones has no significant effect on Chlorella pyrenoidosa C-212 growth and productivity; (2) as the concentration increased, cell movement results in increased productivity of a shallow reactor, with incident light intensities per unit volume as high as $8125 \mu \mathrm{mol} \times \mathrm{m}^{3} \times \mathrm{s}^{-1}$ at the surface; (3) in deep zones of a reactor where the light intensity per unit volume is less than $2000 \mu$ mol $\times \mathrm{m}^{3} \times \mathrm{s}^{-1}$, movement of cells does not improve algae growth rate; (4) for Spirulina platensis M-135, movement of cells always leads to increased productivity, even at low concentrations. 
The above conclusions from literature imply that the flow field should be designed so that algae cells move with a certain frequency between the light and dark zones in order to obtain higher algal growth rate. For better utilization of sunlight, shallow algal raceways may be the right choice for increased productivity of algae and increased concentration during the harvest phase. No matter what types of raceway is used, good flow mixing is important because it leads to better diffusion of nutrients and $\mathrm{CO}_{2}$ in water, and the frequent exposure of all algae cells to sunlight (Wu et al., 2004; Bronnenmeier et al., 1982; Vejrazka et al., 2012; James et al., 2013).

The current study focuses on a shallow algae raceway design, the High Velocity Algae Raceway Integrated Design (ARID-HV). The design of the model was first proposed by Waller et al. (2012) to have a better thermal management by draining the water from the raceway to a canal to avoid heat loss at night. As seen in Fig. 1, the entire algal farming area is essentially constructed as a single serpentine channel, formed by multiple dams with slots near the sidewalls, one after another. The base/ground of the entire raceway area has a general cross slope, so that water can flow down from the top channel to the bottom channel by gravitational force. During a cold time, the water in raceway can be drained down into the canal to avoid freezing. The algae growth rate in the ARID raceway has been shown to have higher yield than conventional pond raceways (Xu et al., 2012).

<Fig. 1 [17]>

Observations of the flow field of the ARID-HV raceway's initial version showed that the flow has 'dead zones' where the serpentine channel bends. As indicated in Fig. 2(a), due to the $180^{\circ}$ bending of the flow and the flow reattachment, a recirculation zone (or 'dead zone') is formed at the corner of a flow channel. Understandably, the flow mixing in the recirculation zone can be rather weak. To enhance the flow mixing in the dead zone, a concept of spillover flow was proposed by the current authors (Xu et al., 2012; Attalah et al., 2012; Xu et al., 2014) to operate the raceway. The concept requires that the water flow rate and the dimensions of dams forming the channels are properly arranged so that the water flow in an upstream channel can spill over the dams and mix with the main serpentine flow in the downstream channel. This mixing is expected to give rise to a spirally forwarding flow (Xu et al., 2014), as illustrated in Fig. 2(b), which can cycle algal cells from bottom to top and vice versa.

<Fig. 2> 
Other new ideas of enhancing the flow mixing in the dead zones of ARID-HV include arranging slots on top of the dam at the dead zone, as shown in Fig. 3. These slots are expected to allow a small amount of water from the upper channel to directly flush into the dead zones of the lower channel via gravity-driven acceleration to promote flow mixing.

\section{<Fig. 3>}

While these above-mentioned approaches for flow mixing enhancement may solve the problem of dead zones, one must have a quantitative measure to evaluate flow mixing.

Because good flow mixing also plays a crucial role in many other industrial processes, such as combustion in engines and chemical reaction in reactors, a number of studies have been conducted to find a method to evaluate flow mixing for different applications. Danckwerts (1958) and Zwietering (1959) defined the relative degree of mixing, using the ratio of the variance of all the molecules' ages to the variance of mean age of all points in a continuous flow system. Liu (2011) further developed this method and extended it to a general steady-state flow system based on the recently developed mean age theory (Liu et al., 2010; Baléo et al., 2000). Because entropy is a measure of the disorder level in the system, it could be one parameter to represent the flow mixing level in a system. Patmore and Toumi (2006) used this parameter to measure the mixing at the tropopause by introducing a quantitative analysis based on entropy to provide climatology of mixing, from $\mathrm{H}_{2} \mathrm{O}: \mathrm{O}_{3}$ tracer correlations. Some researchers in the field of micro-electromechanical system (MEMS) also used this entropy-based measure to evaluate flow mixing. Camesasca el al. (2005) studied the flow mixing in microchannels using numerical simulation with various geometries and employing the conditional Shannon entropy to quantify the dynamics of mixing. Liu et al. (2004) proposed a criterion index of mixing to evaluate the flow mixing in a microchannel through a CFD study. Hsieh et al. (2013) conducted CFD analysis to Y-type micromixers and an optimal $\alpha$, defined as the mixing angle of microchannels, was obtained based upon the proposed mixing efficiency and mixing length. Minakov et al. (2013) also used the concept of mixing efficiency to study the flow mixing in a T-shaped microchannel using CFD.

After carful examining, the methods mentioned above are believed not suitable for the current application for algal raceway, because they cannot reveal the nature of fluid particles being tumbled between surface and bottom or 
staying in the dark zones for a certain period or time. To capture this information, the authors proposed a new method to evaluate the flow mixing in the raceway, which may also be extended to other engineering applications.

In the currently proposed method, the statistics of temporal and spatial distribution of the so-called massless fluid particles in the raceway is studied by collecting the data of pathlines of fluid particles from CFD results. In this approach, the number of cycle counts that a fluid particle passes across a critical depth Dc, as well as the time fraction that the particle stays above Dc during one flow path in the raceway, is counted in order to evaluate the flow mixing performance.

To provide experimental evidence and validation to the CFD simulated flow field as well as the flow mixing evaluations for the proposed ARID-HV raceways, a table-sized raceway was constructed in the laboratory. The following sections will present details of experimental setup and CFD modeling.

\section{Experimental Setup}

This section gives the details of the serpentine flow channel design and dimensions of the table-sized ARID-HV raceway, as well as the experimental setup to visualize the flow field in the raceway. The CFD study in the next section is also for this table-sized ARID-HV raceway, for which details of the flow field and the pathlines of massless particles are obtained. Evaluation of the flow mixing is then conducted using the CFD data.

\subsection{Table-sized ARID-HV testing model}

A table-sized testing model for the proposed ARID-HV raceway has been constructed. The model has an overall length of $1.4 \mathrm{~m}$ and width of $0.7 \mathrm{~m}$, which means that each turn of the serpentine flow channel is also $0.7 \mathrm{~m}$ long. The outer boundary of the model is a wall with a height of $\mathrm{H}=0.12 \mathrm{~m}$. There are 6 turns in the serpentine channel and 5 dams in the entire flow field, with the ratio W/D equal to 5. According to open water channel shallow flow assumption in hydrology (Vreugdenhil, 1994; Henderson, 1996; ), the distance (W) between two dams (forming flow channels) and the depth (D) of water in the channel should have a ratio:

$$
W / D \geq 5
$$

where the depth $\mathrm{D}$ of the water is essentially the height of the dams in this setup. The authors have done a series of tests and CFD studies previously, and proved that when this ratio was equal to 5, the table-sized ARID-HV system 
had a better flow mixing compared to the flow field with $\mathrm{W} / \mathrm{D}=6$ (Xu et al., 2014). Therefore, in the current study, the ARID-HV raceway has a ratio of $\mathrm{W} / \mathrm{D}=5$.

In this work, the Reynolds number of the open channel flow is in the range of turbulent flow. Keeping the same Reynolds number is the criterion of scaling up the raceways. When the W/D is sufficiently large (large than 5), the hydraulic diameter of the flow channel turns to be only a function of the water depth. Due to the requirement of sufficient light intensity for algal cells at the bottom of raceways, the water depths in the table-sized model and in a full size raceway have to be maintained more or less similar. Therefore, keeping the same Reynolds number for open channel shallow-water flow is the criterion of scaling up the raceways from lab scale to full size.

The testing system, as shown in Fig. 4, consists of a water reservoir, a water circulation pump, connecting pipes, valves, and a flow meter. The model was constructed using Plexiglas plates with thickness of $12.25 \mathrm{~mm}$. The water depth and spillover flow across the dams were controlled by varying the dam's height and spacing, as well as the water flow rate. All the dimensions of the table-sized raceway are given in Table 1.

$<$ Fig. 4>

$<$ Table 1>

A point velocity meter (LGY-II Velocity Meter, Haocheng Inc.), with accuracy of $0.01 \mathrm{~cm} / \mathrm{s}$, was used to measure the water flow velocity in channels at any local point. A CCD camera was used to record the dye dispersion in the flow during flow visualization. The maximum flow rate available from the pump was $7.0 \times 10^{-2} \mathrm{~m}^{3} / \mathrm{min}$.

\subsection{Different geometries of dams for the serpentine flow channels}

According to the experiments previously done by the team for the initial version of the raceway design (Xu et al., 2012), flow dead zones were observed, where the dye injection could hardly spread out. This means that at these dead zones, limited exchange of mass/momentum results in insufficient flow mixing. Therefore, a modification is proposed here: to cut the slots on the top of the dams near the dead zones. Consequently, five dam structures, with four of them having different sets of slot geometries, shown in Fig. 3, were designed for the tests. Dimensions and locations of these slots on top of dams are listed in Table 2. 
$<$ Table 2>

\subsection{Flow visualization setup and procedures}

The flow visualization in this study was designed to qualitatively validate the CFD predicted results and also evaluate the flow mixing in the table-sized ARID-HV raceway using the proposed method. During the experiments, a steady-state flow was maintained. There are six turns of the serpentine channels, and the flow should be fully established after the first two channels; therefore, the flow field in the fourth channel/turn was believed to be representative and thus was selected for visualization, as indicated in Fig. 5(a). At selected locations, red dye was injected using a very fine tube with a $1.59 \mathrm{~mm}$ outer diameter at halfway between the base and water surface. Nine out of the fifteen locations, as marked in Fig. 5(b), were individually tested with dye injection and visualization. The nine locations of visualization tests were 1, 2, 3, 7, 8, 9, 13, 14, and 15. Flow velocities at all the fifteen locations were also measured to help validate the CFD results. The volumetric flow rate was $2.4 \times 10^{-2} \mathrm{~m}^{3} / \mathrm{min}$, which resulted in a water velocity of $0.7 \mathrm{~m} / \mathrm{s}$ at the exit of the pipe (in diameter of $25.4 \mathrm{~mm}$ ) which feeds water to the raceway. After

inlet, the water velocity in the raceway flow channel becomes $0.13 \mathrm{~m} / \mathrm{s}$, which is typically chosen for algae growth. The outlet tube had an inner diameter of $50.8 \mathrm{~mm}$ at the end of the serpentine channel.

<Fig. 5>

The injection of red dye lasted for 10 seconds at each test at an individual location. Upon cessation of dye injection (10 seconds), photos were taken to visualize the dye-spread area. The amount of dye injected in 10 seconds was exactly the same for all tests. All photos were taken under the same visualization conditions so that the flow mixing could be compared between cases of different flow rates and raceway structures.

\section{CFD methodology}

Numerical simulations were carried out to help analyze the flow field of the table-sized ARID-HV raceway and to obtain detailed data about the pathlines of fluid particles for the evaluation of flow mixing performance. The commercial software ANSYS Fluent $^{\circledR}$ 6.3.26 was chosen for this analysis. The flow in the raceway is a turbulent, shallow-water, incompressible, and unsteady flow with constant properties. Three-dimensional Navier-Stokes 
equations for turbulent flow with free surface were applied. A standard $k-\omega$ turbulence model was applied, because $\mathrm{k}-\omega$ model can capture the stretching and rotating in the flow field more accurate than any other RANS model. The free surface of water-air was captured by using the VOF (Volume of Fluid) model (Štrubelj et al., 2009; Ramamurthy et al., 2007). Maintaining identical inlet flow conditions, flow fields due to different dam geometries were simulated. The key features of the numerical treatment are described by Xu et al. (2014).

\subsection{Boundary conditions}

a) The inlet water velocity was $0.7 \mathrm{~m} / \mathrm{s}$, which was chosen based on studies by Richmond and Vonshak (1978).

b) All solid walls in the raceway had non-slip velocity conditions: $u_{i}=0$.

c) At the air/water free surface: $\partial u_{i} / \partial z=0, p=p_{0}$ (equal to $1.0 \mathrm{~atm}$ ).

d) At the exit of the raceway, a pressure outlet $(1.0 \mathrm{~atm})$ boundary condition (one of the flow exit boundary condition treatment methods in ANSYS Fluent ${ }^{\circledR}$ ) was used.

e) Depth of the computational domain was set to be $10 \mathrm{~cm}$, including water, air and the interface. Initially the water depth was set as $6 \mathrm{~cm}$ in the computational domain.

f) Initial velocities for the computation of the initial period (10s) were assumed zero. After that, any computation for continued periods of flow will use the velocities from the end of the last period as the initial velocities.

\subsection{Computational procedures and grid dependence study}

Following the standard computational steps of ANSYS Fluent ${ }^{\circledR}$ 6.3.26, the computational domain was generated using Gambit ${ }^{\circledR}$ 2.4.6. The time step of computation for the transient process was set as 0.001 seconds for a total time length of 10 seconds. The second-order upwind scheme was chosen for the discretization of the convection terms in the governing equations, and the PISO algorithm, which was suitable for capturing the free surface, was used to treat the coupling of the pressure and momentum equations. The computation was for transient flow. The flow field was found in steady state after 10 seconds. All flow velocities and pressures at the moment of 10 seconds were recorded to serve as the initial flow field for the next 10 second simulation, from which the pathlines of massless particles can be obtained. Since the computed flow time is sufficiently long, steady state results were able to be obtained. 
A grid-dependence study was conducted to choose an appropriate grid number that ensures the accuracy of computational results for a reasonable computational cost. For the computational domain, cell numbers of 1.85 million, 3.71 million, and 7.41 million were evaluated. The velocities at half water depth at point 8 (shown in Fig. 5(b)) were examined for all the cases at $20 \mathrm{~s}$ after the transient process started. It was found that the relative difference of the velocity at that point varied by $10 \%$ by increasing the cell number from 1.85 million to 3.71 million. Further increasing of the cell number from 3.71 million to 7.41 million resulted in a relative velocity difference of $0.33 \%$. Thus, 3.71 million cells were used for the computational domain in all the computations from which results and conclusions were drawn. Other than the refinement of the entire flow field grid, local grid refinement was given to regions at the corner of each dam and connected side wall of the raceway. One example of the local grid refinement for the case of two slots is shown in Fig. 6.

<Fig. 6>

\section{The proposed method of evaluating flow mixing performance}

For the flow mixing evaluation, the pathlines of massless fluid particles were estimated from our CFD results. Pathlines are used to visualize the flow of massless particles in the computational domain, and they are also the trajectories that individual fluid particles follow, which can be thought of as "recording" the path of a fluid element in the flow over a certain time period. In this study, particles were released from the inlet of the raceway at the moment when water flows in. The initial conditions of the flow field at this moment were based on the steady state results from a preset simulation. As a result, from the simulated flow field results in the next 10 seconds, the pathlines of massless particle can be obtained. Every cell/mesh at the inlet surface had one particle, and the data of particles was used to calculate the temporal and spatial distributions of fluid particles with respect to critical depth $D c$, which is the maximum depth that sunlight can penetrate. It is important to note that for a large-scale algal raceway, the critical water depth should be determined by the penetration depth of incident light with respect to local conditions.

The concept of cycle count of particles was introduced in this work. The fluid particles, following the spirally forwarding vortex, will pass through $D_{C}$ many times during one flow path from inlet to outlet of the raceway. If a 
fluid particle $i$ passes through $D_{C}$, then this is counted as one cycle count, $M_{i}$. The number of cycles for each flow path from CFD is accumulated for each particle. Then, the distribution of the number of particle cycle counts is calculated, which is referred to as the spatial distribution of fluid particles.

More cycle counts indicates more intense flow mixing. However, the cycle count distribution of fluid particles alone does not completely reflect the time lapse from one cycle count to another. Therefore, the time fraction of a particle staying above $D_{C}$ was calculated to evaluate the intensity of flow mixing. The time period that a fluid particle $i$ being above $D_{C}$ is defined as $T_{i}^{u p}$ and that below $D_{C}$ as $T_{i}^{\text {down }}$. Therefore, the time period that a fluid particle $i$ stays above $D_{C}$ against the total time period $T_{i}^{d o w n}+T_{i}^{u p}$ is expressed as:

$$
P_{i}=\frac{T_{i}^{u p}}{T_{i}^{d o w n}+T_{i}^{u p}}
$$

The number of fluid particles that fall into a certain range of $P_{i}$ was counted and normalized by the total number of particles, which is referred to as the temporal distribution of fluid particles.

According to the conclusions of Lee and Pirt (1981), Merchuk et al. (1998), and Ogbinna et al. (1995), photosynthesis continues for a short period of time without light until all of the stored energy and intermediate products are consumed. After that, growth stops and endogenous respiration may take place, leading to a decrease in

cell concentrations. To consider this point, there is a threshold value $P_{i}^{\text {thresh }}$ for efficient light/dark mixing that optimizes algal growth. The closer $P_{i}$ is to the threshold value, the more effective the flow mixing is.

To the opinion of the authors, the cycle count and the time fraction above $D_{C}$ need to be both considered to evaluate the flow mixing performance. Neither individually reflects the true nature of flow mixing (Xu et al., 2013). An example application measuring flow mixing in the table-sized ARID-HV raceway is presented next.

\section{Results and Discussion}

This section presents the CFD results and flow mixing evaluation for the constructed table-sized ARID-HV testing system. First, the CFD results were verified with measured local velocities in the test system, and then flow mixing was evaluated quantitatively. Finally, photographic results of flow visualization build confidence in the proposed method of flow mixing evaluation. 


\subsection{Verification of CFD results with measured local flow velocities}

Water flow velocities at 15 points were measured to verify the CFD results. The data of the average of three times of measurement are presented here. Measurement points are located at the middle of the flow channel and at half the depth of the water, Points 2, 5, 8, 11, and 14 in Fig. 5(b). The measured and simulated velocities at these points are listed in Table 3. Relatively small differences were observed at Points 2, 5, 8 and 11, from $0.67 \%$ to 20\%, while only one case showed the CFD result was $29.6 \%$ different from the measured data for four slots case at Point 11. At point 14 , the relative differences between simulation and experiments were slightly larger, ranging from $20 \%$ to 30\%. Nevertheless, the majority of the measured data agreed well with the CFD results, which generally verified the validity of the CFD approach and the obtained results.

$<$ Table 3>

\subsection{Numerical simulations}

The current CFD work analyzed five raceway designs with a different numbers of cutting slots on the top of the dams that improve the mass/momentum transfer at the dead zones, as illustrated in Fig. 1.

Fig. 7 shows the pathlines from inlet to outlet of the table-sized ARID-HV raceway for the five types of slot geometries. The pathlines illustrate the spirally forwarding vortex in each channel, which had been verified previously in the ARID-HV raceway of the original design (Xu et al., 2012). In the current modified design with slots on dams, CFD results show more pathlines passing through the dead zones, and this indicates that the flow

field has better mixing than if no slots are present. Fig. 8 presents the velocity contours at three cross-sections along the width of the table-sized raceway. It's clear that with an increased numbers of slots, the cross-over or spillover flow increases. This is another indication that the flow mixing improves due to the slots on top of the dams.

<Fig. 7>

<Fig. 8>

These slots also minimize dead zones observed in earlier versions with no slots for ARID-HV. Velocity contours at the mid-height of the slots are shown in Fig. 9. The circles in Fig. 9 (a) show the dead zones. However, 
by cutting slots, Fig. 9 (b) - (e) clearly show that water flushes into the dead zones through these slots, which results in dramatically minimizing or eliminating of the dead zones for all but Set 1.

<Fig. 9>

From Fig. 8 and 9, it is clear that cutting slots on top of the dams promotes flow mixing and minimizes dead zones. The so called dead zone in this study represents the area, especially at the corner of a dam and the side wall (by gray lines/frames shown in Fig. 10) where the flow mixing is weak due to very low velocity or due to a recirculation region that limits flow mixing. Fig. 10 shows the flow velocity vectors at the mid-height of the slots on top of the dam for the second dam in the flow field. Fig. 10 (a) has no slot on the dam. A vortex region is seen and the flow on the other side of the dam has rather low velocity. In the case of having slots on top of the dam, the vortex is minimized and also the flow velocity on the other side of the dam is increased. It is noted that a quantitative evaluation to the volume or area of the dead zones is still difficult to define due to the 3D nature of the flow field.

$<$ Fig. 10>

\subsection{Flow mixing evaluation of five different experiments}

This study gave an effort to quantitatively evaluate the mixing of flow in the explored flow fields. The critical depth was set to $2.5 \mathrm{~cm}$ when evaluating flow mixing. For a large-scale ARID-HV raceway, the critical water depth should be determined by the light penetration depth as a function of incident light and algal culture density.

From CFD results, the cycle count and the time period of particles staying above/below $D_{C}$ for every single particle can be computed, and the distributions of cycle count and time period fraction are given in Table 4 and Table 5 .

$<$ Table 4>

$<$ Table 5> 
The histogram in Fig. 11 shows the cycle count distribution of fluid particles in the simulated ARID-HV raceway with different numbers of slots on top of dams. A cycle count between 6 and 20 is assumed to offer a level of flow mixing that does not require excessive algal culture pumping energy but also cycles algae into the light frequently enough to prevent growth rate reduction. Cycle counts below 6 may have insufficient mixing, while more than 20 may be more than necessary. From Table 4 and Fig. 11, the no-slot case has $45 \%$ of fluid particles with cycle counts between 6 and 20, while the percentage of particles for the one-slot case is 40\%, and for the two-slot case is $36 \%$. For the three and four-slot cases, the percentages of particles with the optimal frequencies are $26 \%$ and $20 \%$, respectively. If we assume that $30 \%$ is the minimum required percentage of fluid particles that have cycle count in the range of 6 to 20, then Fig. 11 indicates that Cases 1, 2, and 3 have acceptable flow mixing while Cases 4 and 5 do not.

$\langle$ Fig. 11>

While the cycle counts provided useful information about flow mixing, it is also important to know how long algal cells stay in dark zones (Foy et al., 1976; Lee et al., 1981; Merchuk et al., 1998). The time that particles stay above/below the critical depth $D_{C}$ of $2.5 \mathrm{~cm}$ was also examined. If a threshold value $P_{i}^{\text {thresh }}$ is defined, the flow field with a better mixing will lead to the fact that the time period fraction of fluid particles staying above/below $D_{C}$

approaches the threshold value of $P_{i}^{\text {thresh }}$. It is assumed in this paper that for $P_{i}^{\text {thresh }}$ being between 0.4 and 0.6 , so the period of time that particles stay above and below $D c$ is about equal.

$<$ Fig. 12>

Fig. 12 shows histograms of particles within various ranges of $P$. From the previous analysis, Cases 1,2 , and 3 were considered to have relatively good flow mixing, so $P_{i}$ will only be evaluated for these. As shown in Table 5 for Case 1, 36\% of the fluid particles were above $D_{C}$ for $40-60 \%$ of the time, Case 2 had about $29 \%$ of the particles staying $40-60 \%$ of the time above $D_{C}$, and Case 3 had slightly higher percentage, $37 \%$ of the particles stayed between $40-60 \%$ of the time. In Cases 4 and 5, 28\% and 29\%, respectively, of particles spent 40-60\% of their 
time above $D_{C}$. Comparing these cases, Sets 2, 4, and 5 had smaller time fractions (around 29\%) above $D_{C}$, while Cases 1 and 3 had a larger time fraction (around 36\%), which is an indication of improved flow mixing. Considering both the statistics of cycle count distribution and the time fraction distribution that particles stay above $D_{C}$, Cases 1 and 3 show the best flow mixing.

Although the analysis to the particles' spatial and temporal statistics gave a good example of evaluating flow mixing in a raceway, flow mixing evaluation in a raceway using the currently proposed method will virtually depend on the criteria of $D_{C}, P_{i}^{\text {thresh }}$, and the required cycle counts that are provided by algae biologists or engineers.

\subsection{Flow visualization results}

The photographs in Fig. 13 visualize flows at the 6 points (points 1, 2, 7, 8, 13, 14) indicated in Fig. 5. From left to right, the photographs are for raceway models Sets 1, 2, 3, 4 and 5.

$<$ Fig. 13>

Because of consistency of dye injection across experiments, the area over which dye spreads corresponds to the flow mixing intensity. As a result, flow visualization can validate with the simulations. Raceway Sets 1 and 3 show the most extensive dye dissipation. This is consistent with simulations, which suggested that Sets 1 and 3 have good flow mixing with more cycle counts and larger time fraction staying on top of $D_{C}$.

Comparing the dissipating area in pictures between Set 1 and Set 3 carefully, it is seen that Set 3 has a larger dye dissipating area, which indicates that Set 3 has the best flow mixing among the five different experimental sets. As a consequence, again, a final conclusion of merit of the flow mixing in raceways Sets 1 and 3 using the currently proposed method should be made based on the criteria of $D_{C}, P_{i}^{\text {thresh }}$, and the required cycle counts.

The pixel of dye-colored area on the picture was counted for quantitative evaluation to the dye-dissipated area. Fig. 14 gives the ratio $S^{*}$ of the dye-colored area (by counting pixel of colored region) against the entire area of the picture. It is again seen that the dye-colored area for the case with two slots on the dam is relatively larger than that of other cases. 
$<$ Fig. $14>$

\subsection{Time period staying in darkness}

According to the conclusions from Lee et al. (1981) and Merchuk et al. (1998), it is reasonable to assume that microalgae cells respond instantaneously to variations in light intensities but exhibit a delay of at least $5 \mathrm{~s}$ following complete darkness before biomass loss due to respiration in darkness. This implies that if algae cells stay in full darkness shorter than $5 \mathrm{~s}$, there will be no loss of production. From CFD results, we can easily obtain how long the

fluid particles would stay in darkness by integrating $T_{i}^{\text {down }}$ for each particle, and similarly we also can show a histogram to demonstrate the time fraction of fluid particles staying in darkness.

In fact, ARID-HV raceways may be designed to have shallow water to completely avoid darkness. Also, for different strains of algae, the criterion of time limit in darkness may be different. Therefore, for the table-sized ARID-HV testing system, the time period of fluid particles staying in darkness has not been checked. Nevertheless, the main purpose of this paper was to demonstrate the application of the new method to evaluate flow mixing. This method can be applied to any actual large scale ARID-HV algae raceways.

\section{Conclusions and remarks}

This paper proposed a new method to use CFD results to evaluate flow mixing using temporal and spatial distribution of fluid particles. This method was applied to a table-sized ARID-HV raceway to quantify the flow mixing performance of five experimental sets with various geometries of dams. After CFD analysis was completed, the data of pathlines regarding their locations at any time was processed to obtain the statistics of temporal and spatial distribution and to evaluate flow mixing. The evaluation using the criteria proposed in this work has found that the design with two slots on the dams is a very good choice. After that, a flow visualization test was conducted to validate the CFD result, which agreed quite well. We hope this method can be employed in evaluation of algal raceway flow fields as well as other engineering applications.

In this work, the Reynolds number indicates the flow is turbulent. Keeping the same Reynolds number for this type of open channel flow is the criterion of scaling up the raceways from lab scale to full size. When the W/D is sufficiently large (larger than 5), the hydraulic diameter of the flow channel is only a function of water depth. 
Therefore, keeping the same Reynolds number for open channel shallow-water flow is the criterion of scaling up the raceways from lab scale to full size.

\section{Acknowledgment}

The authors are grateful to the funding from the U.S. Department of Energy National Alliance for Advanced Biofuels and Bioproducts (NAABB). Thanks are also due to Mr. Randy Ryan from the College of Agriculture, and Mr. Said Attalah and Mr. George Khawam in the Department of Agriculture and Biosystem Engineering at the University of Arizona for their help and valuable discussions.

\section{Nomenclature}

$\mathrm{D}$

$D_{C}$

G

$\mathrm{L}$

$M_{i}$

$\mathrm{P}_{\mathrm{i}}$

$$
P_{i}^{\text {thresh }}
$$

$T_{i}^{u p}$

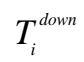

$\mathrm{V}$

W

$\mathrm{X}_{1}$

$\mathrm{X}_{2}$

$\mathrm{X}_{3}$

$\mathrm{Z}_{\mathrm{S}}$

$S^{*}$ water depth, unit: $\mathrm{m}$

critical water depth for algae growth, unit: $\mathrm{m}$

gap distance between the dam end and the raceway sidewall, unit: $\mathrm{m}$

length of the dam, unit: $m$

cycle count of the $i$ th fluid particle

percentage of time period above $D_{C}$ taken up the total time period of the $i$ th fluid particle

threshold value $P_{i}^{\text {thresh }}$ of time period fraction above the critical water depth $D_{C}$

time period of the $i$ th fluid particle above $D_{C}$, unit: second

time period of the $i$ th fluid particle below $D_{C}$, unit: second

inlet velocity, unit: $\mathrm{m} / \mathrm{s}$

channel width, unit: $m$

distance between the first slot and the raceway sidewall on each dam, unit: $\mathrm{m}$

length of the slot on each dam, unit: $\mathrm{m}$

distance between two slots on each dam, unit: $\mathrm{m}$

height of each slot, unit: $\mathrm{m}$

the ratio of the dye-colored area against the total area in each flow visualization picture 


\section{References}

Attalah S., Waller, P., Khawam, G., Ryan R., Energy evaluation in the High Velocity Algae Raceway Integrated Design (ARID-HV). Proceedings of the 2012 ASABE Annual International Meeting. July 29-August 1, 2012, Dallas, Texas, USA.

Baléo, J. N., Le Cloirec, P., 2000. Validating a prediction method of mean residence time spatial distributions. AIChE journal, 46(4), 675-683.

Beal, C. M., Hebner, R. E., Webber, M. E., 2012. Thermodynamic analysis of algal biocrude production. Energy, 44(1), 925-943.

Bronnenmeier, R., Märkl, H., 1982. Hydrodynamic stress capacity of microorganisms. Biotechnology and bioengineering, 24(3), 553-578.

Camesasca, M., Manas-Zloczower, I., Kaufman, M., 2005. Entropic characterization of mixing in microchannels. Journal of Micromechanics and Microengineering, 15(11), 2038.

Danckwerts, P. V., 1958. The effect of incomplete mixing on homogeneous reactions. Chemical Engineering Science, 8(1), 93-102.

Foy, R. H., Gibson, C. E., Smith, R. V., 1976. The influence of daylength, light intensity and temperature on the growth rates of planktonic blue-green algae. British phycological journal, 11(2), 151-163.

Henderson, F. M., 1989. Open channel flow. Macmillan.

Hsieh, S. S., Lin, J. W., Chen, J. H., 2013) Mixing efficiency of Y-type micromixers with different angles. International Journal of Heat and Fluid Flow,44, 130-139.

James, S. C., \& Boriah, V., 2010. Modeling algae growth in an open-channel raceway. Journal of Computational Biology, 17(7), 895-906.

Kromer, M. A., Bandivadekar, A., Evans, C., 2010. Long-term greenhouse gas emission and petroleum reduction goals: evolutionary pathways for the light-duty vehicle sector. Energy, 35(1), 387-397.

Kucukvar, M., Tatari, O., 2011. A comprehensive life cycle analysis of cofiring algae in a coal power plant as a solution for achieving sustainable energy. Energy, 36(11), 6352-6357.

LEE, Y. K., PIRT, S. J., 1981. Energetics of photosynthetic algal growth: influence of intermittent illumination in short (40 s) cycles. Journal of General Microbiology, 124(1), 43-52. 
Liu, M., Tilton, J. N., 2010. Spatial distributions of mean age and higher moments in steady continuous flows. AIChE journal, 56(10), 2561-2572.

Liu, M., 2011. A method for computing the degree of mixing in steady continuous flow systems. Chemical Engineering Science, 66(13), 3045-3048.

Liu, Y. Z., Kim, B. J., Sung, H. J., 2004. Two-fluid mixing in a microchannel.International journal of heat and fluid flow, 25(6), 986-995.

Marshall, J. S., \& Huang, Y., 2010. Simulation of light-limited algae growth in homogeneous turbulence. Chemical Engineering Science, 65(12), 3865-3875.

Merchuk, J. C., Contreras, A., Garcia, F., Molina, E., 1998. Studies of mixing in a concentric tube airlift bioreactor with different spargers. Chemical Engineering Science, 53(4), 709-719.

Merchuk, J. C., Garcia-Camacha, F., Molina-Grima, E., 2011. Photobioreactors - Models of Photosynthesis and Related Effects. Comprehensive Biotechnology (Second Edition) 2, 227-247.

Minakov, A., Rudyak, V., Dekterev, A., Gavrilov, A., 2013. Investigation of slip boundary conditions in the T-shaped microchannel. International Journal of Heat and Fluid Flow, 43, 161-169.

Ogbonna, J. C., Yada, H., Tanaka, H., 1995. Effect of cell movement by random mixing between the surface and bottom of photobioreactors on algal productivity. Journal of fermentation and bioengineering, 79(2), $152-157$.

Patmore, N., Toumi, R., 2006. An entropy- based measure of mixing at the tropopause. Quarterly Journal of the Royal Meteorological Society, 132(619), 1949-1967.

Ramamurthy, A. S., Qu, J., Vo, D., 2007. Numerical and experimental study of dividing open-channel flows. Journal of Hydraulic Engineering, 133(10), 1135-1144.

Richmond, A., Vonshak, A., 1978. Spirulina culture in Israel. Arch. Hydrobiol. Beih., Ergebn. Limnol, 11, $274-280$.

Štrubelj, L., Tiselj, I., Mavko, B., 2009. Simulations of free surface flows with implementation of surface tension and interface sharpening in the two-fluid model. International Journal of Heat and Fluid Flow, 30(4), $741-750$.

Sun, A., Davis, R., Starbuck, M., Ben-Amotz, A., Pate, R., Pienkos, P. T., 2011. Comparative cost analysis of algal oil production for biofuels. Energy, 36(8), 5169-5179.

Vejrazka, C., Janssen, M., Streefland, M., Wijffels, R. H., 2012. Photosynthetic efficiency of Chlamydomonas reinhardtii in attenuated, flashing light. Biotechnology and bioengineering, 109(10), 2567-2574.

Vreugdenhil, C. B., 1994. Numerical methods for shallow-water flow (Vol. 13). Springer. 
Waller, P., Ryan, R., Kacira, M., Li, P., 2012. The algae raceway integrated design for optimal temperature management. Biomass and Bioenergy, 46, 702-709.

Wang, H., Pang, Y., 2008. Numerical simulation on hydrodynamic character for algae growth. Environmental Science 29, 885-889.

Wu, X., Merchuk, J. C., 2004. Simulation of algae growth in a bench scale internal loop airlift reactor. Chemical Engineering Science, 59(14), 2899-2912.

Xu, B., Li, P., Waller, P., Study of the flow mixing in a novel open-channel raceway for algae production. Proceedings of the ASME 2012 6th International Conference on Energy Sustainability. July 23-26, 2012, San Diego, CA, USA.

Xu, B., Li, P., Waller, P., Optimization of the Flow Field of a Novel ARID Raceway (ARID-HV) for Algal Production. Proceedings of the ASME 2013 7th International Conference on Energy Sustainability. July 14-19, 2013, Minneapolis, MN, USA

Xu, B., Li, P., Waller, P., 2014. Study of the flow mixing in a novel ARID raceway for algae production. Renewable Energy, 62, 249-257.

Zwietering, T. N., 1959. The degree of mixing in continuous flow systems.Chemical Engineering Science, 11(1), $1-15$. 


\section{Figure Caption}

Fig. 1 An ARID-HV algal raceway concept and dimensions

Fig. 2 Schematic of ARID-HV raceway flow field

Fig. 3 Schematic of five different sets of geometries of dams for the table-sized ARID-HV raceway

Fig. 4 Schematic of the table-sized raceway test system setup

Fig. 5 Locations of visualization and velocity test in the raceway

(a) Flow visualization setup; (b) 15 test points in the $4^{\text {th }}$ channel.

Fig. 6 Local mesh refinement at near dam regions

Fig. 7 Particles' pathlines from the inlet to outlet in the raceway

Fig. 8 Velocity contours at three cross sections along the width of the raceway (Units: $\mathrm{cm} / \mathrm{s}$ )

Fig. 9 Velocity contours at the middle-height of slots in $x-y$ plane $($ at $z=41.9 \mathrm{~mm})($ Units: $\mathrm{cm} / \mathrm{s})$

Fig. 10 Velocity vectors at the mid-height of slots in $x-y$ plane $($ at $z=41.9 \mathrm{~mm})($ Units: $\mathrm{cm} / \mathrm{s})$

Fig. 11 Distribution of the fluid particles' cycle counts

(The horizontal axis gives the ranges of the cycle counts; the vertical axis represents the percentage of fluid particles that fall in the ranges of cycle counts)

Fig. 12 Distribution of fluid particles' time fractions above a critical depth.

(The horizontal axis represents the range of time fractions that fluid particles were above Dc; the vertical axis represents the percentage of fluid particles that fall in the ranges of time fractions above Dc.)

Fig. 13 Photographs of red dye dissipation from flow visualization

Fig. 14 Ratios of the dye-colored area against the area of the picture 
Tables

Table 1 Dimensions of table-sized ARID-HV raceway

\begin{tabular}{l|l|l|l}
\hline$L(m)$ & 1.4 & $W / D$ & 5 \\
\hline$L^{\prime}(\mathrm{m})$ & 0.7 & $G / W$ & 0.8 \\
\hline$H(m)$ & 0.12 & $W(\mathrm{~mm})$ & 220.63 \\
\hline Channels & 6 & $D(\mathrm{~mm})$ & 44.10 \\
\hline Dams & 5 & $G(\mathrm{~mm})$ & 176.5 \\
\hline
\end{tabular}

Note: $\quad G$ is the gap between the dam end and the raceway sidewall (see Fig. 2(b)) 
Table 2 Dimensions and locations of the slots on dams

\begin{tabular}{llll}
\hline$X_{I}$ & $X_{2}$ & $X_{3}$ & $Z_{S}$ \\
\hline $5.3 \mathrm{~mm}$ & $8.825 \mathrm{~mm}$ & $17.65 \mathrm{~mm}$ & $4.41 \mathrm{~mm}$ \\
$3 \%$ of G & $5 \%$ of G & $10 \%$ of G & $10 \%$ of D \\
\hline
\end{tabular}


Table 3 Measured velocities at local point and comparison with CFD results

\begin{tabular}{|c|c|c|c|c|c|c|c|c|c|c|c|c|c|c|c|}
\hline \multirow[b]{2}{*}{ Point } & \multicolumn{3}{|c|}{ No Slot } & \multicolumn{3}{|c|}{ One slot } & \multicolumn{3}{|c|}{ Two slots } & \multicolumn{3}{|c|}{ Three slots } & \multicolumn{3}{|c|}{ Four slots } \\
\hline & $\begin{array}{c}\text { Test } \\
(\mathrm{cm} / \mathrm{s})\end{array}$ & $\begin{array}{l}C F D \\
(\mathrm{~cm} / \mathrm{s})\end{array}$ & Error & $\begin{array}{c}\text { Test } \\
(\mathrm{cm} / \mathrm{s})\end{array}$ & $\begin{array}{l}C F D \\
(\mathrm{~cm} / \mathrm{s})\end{array}$ & Error & $\begin{array}{c}\text { Test } \\
(\mathrm{cm} / \mathrm{s})\end{array}$ & $\begin{array}{c}C F D \\
(\mathrm{~cm} / \mathrm{s})\end{array}$ & Error & $\begin{array}{c}\text { Test } \\
(\mathrm{cm} / \mathrm{s})\end{array}$ & $\begin{array}{c}C F D \\
(\mathrm{~cm} / \mathrm{s})\end{array}$ & Error & $\begin{array}{c}\text { Test } \\
(\mathrm{cm} / \mathrm{s})\end{array}$ & $\begin{array}{l}C F D \\
(\mathrm{~cm} / \mathrm{s})\end{array}$ & Error \\
\hline 2 & 1.44 & 1.50 & $4.00 \%$ & 1.29 & 1.50 & $14.0 \%$ & 1.24 & 1.50 & $17.3 \%$ & 1.43 & 1.75 & $18.3 \%$ & 1.43 & 1.50 & $4.67 \%$ \\
\hline 5 & 1.51 & 1.50 & $0.67 \%$ & 1.48 & 1.50 & $1.35 \%$ & 1.52 & 1.50 & $1.35 \%$ & 1.62 & 2.00 & $19.0 \%$ & 1.29 & 1.25 & $3.20 \%$ \\
\hline 8 & 1.43 & 1.50 & $4.67 \%$ & 1.58 & 1.50 & $5.35 \%$ & 1.43 & 1.30 & $10 . \%$ & 1.43 & 1.50 & $4.67 \%$ & 1.43 & 1.25 & $14.4 \%$ \\
\hline 11 & 1.29 & 1.50 & $14.0 \%$ & 1.43 & 1.30 & $10.0 \%$ & 1.33 & 1.50 & $11.3 \%$ & 1.58 & 1.50 & $5.33 \%$ & 1.62 & 1.25 & $29.6 \%$ \\
\hline 14 & 1.58 & 2.00 & $21.09 \%$ & 1.58 & 2.00 & $21.0 \%$ & 1.53 & 2.00 & $23.5 \%$ & 1.43 & 2.00 & $28.5 \%$ & 1.39 & 2.00 & $30.5 \%$ \\
\hline
\end{tabular}


Table 4 Statistics of fluid particles' cycle counts passing across a critical depth Dc

\begin{tabular}{|c|c|c|c|c|c|c|c|c|c|c|}
\hline Cycles counts & \multicolumn{2}{|c|}{$\begin{array}{c}\text { No Slot } \\
(192 \text { particles })\end{array}$} & \multicolumn{2}{c|}{$\begin{array}{c}\text { One Slot } \\
(108 \text { particles })\end{array}$} & \multicolumn{2}{c|}{$\begin{array}{c}\text { Two Slots } \\
(108 \text { particles })\end{array}$} & \multicolumn{2}{c|}{$\begin{array}{c}\text { Three Slots } \\
(106 \text { particles })\end{array}$} & \multicolumn{2}{c|}{$\begin{array}{c}\text { Four Slots } \\
(106 \text { particles })\end{array}$} \\
\hline $0-5$ times & 104 & $54.17 \%$ & 63 & $58.33 \%$ & 65 & $60.19 \%$ & 78 & $73.58 \%$ & 85 & $80.19 \%$ \\
\hline $6-10$ times & 63 & $32.81 \%$ & 35 & $32.41 \%$ & 26 & $24.07 \%$ & 23 & $21.69 \%$ & 16 & $15.09 \%$ \\
\hline $11-15$ times & 23 & $11.98 \%$ & 8 & $7.31 \%$ & 10 & $9.26 \%$ & 5 & $4.73 \%$ & 5 & $4.72 \%$ \\
\hline $16-20$ times & 1 & $0.52 \%$ & 0 & $0.00 \%$ & 3 & $2.78 \%$ & 0 & $0.00 \%$ & 0 & $0.00 \%$ \\
\hline$>20$ times & 1 & $0.52 \%$ & 2 & $1.95 \%$ & 4 & $3.70 \%$ & 0 & $0.00 \%$ & 0 & $0.00 \%$ \\
\hline
\end{tabular}


Table 5 Statistics of fluid particles' time fraction staying above a critical depth Dc

\begin{tabular}{|c|c|c|c|c|c|c|c|c|c|c|}
\hline$P_{i}$ & \multicolumn{2}{|c|}{$\begin{array}{c}\text { No Slot } \\
(192 \text { particles })\end{array}$} & \multicolumn{2}{c|}{$\begin{array}{c}\text { One Slot } \\
(108 \text { particles })\end{array}$} & \multicolumn{2}{c|}{$\begin{array}{c}\text { Two Slots } \\
(108 \text { particles })\end{array}$} & \multicolumn{2}{c|}{$\begin{array}{c}\text { Three Slots } \\
(106 \text { particles })\end{array}$} & \multicolumn{2}{c|}{$\begin{array}{c}\text { Four Slots } \\
(106 \text { particles })\end{array}$} \\
\hline $0 \%-20 \%$ & 26 & $13.54 \%$ & 17 & $15.74 \%$ & 26 & $24.07 \%$ & 30 & $28.30 \%$ & 25 & $23.58 \%$ \\
\hline $20 \%-40 \%$ & 62 & $32.29 \%$ & 50 & $46.30 \%$ & 37 & $34.26 \%$ & 39 & $36.80 \%$ & 36 & $33.96 \%$ \\
\hline $40 \%-60 \%$ & 69 & $35.94 \%$ & 31 & $28.71 \%$ & 40 & $37.04 \%$ & 30 & $28.30 \%$ & 31 & $29.24 \%$ \\
\hline $60 \%-80 \%$ & 17 & $8.85 \%$ & 8 & $7.41 \%$ & 4 & $3.70 \%$ & 5 & $4.72 \%$ & 11 & $10.38 \%$ \\
\hline $80 \%-100 \%$ & 18 & $9.38 \%$ & 2 & $1.84 \%$ & 1 & $0.93 \%$ & 2 & $1.88 \%$ & 3 & $2.84 \%$ \\
\hline
\end{tabular}




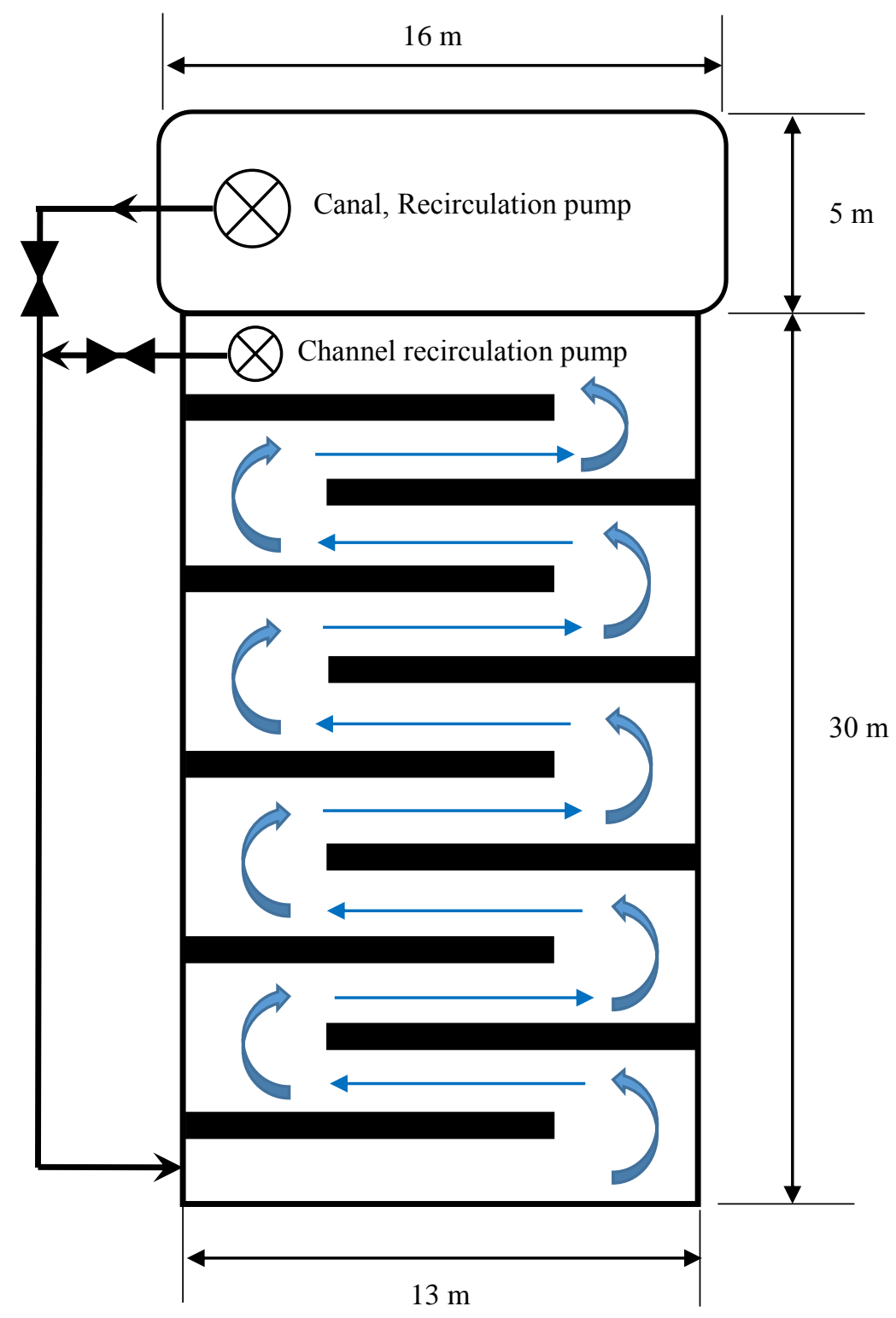

Fig. 1 


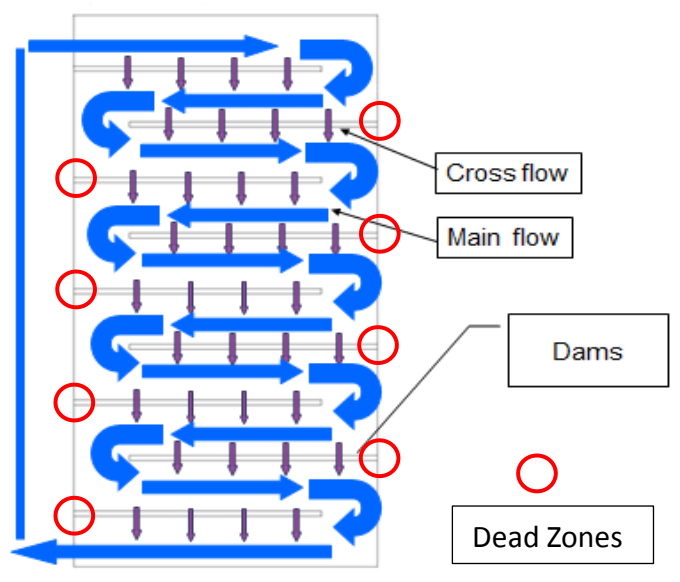

(a)

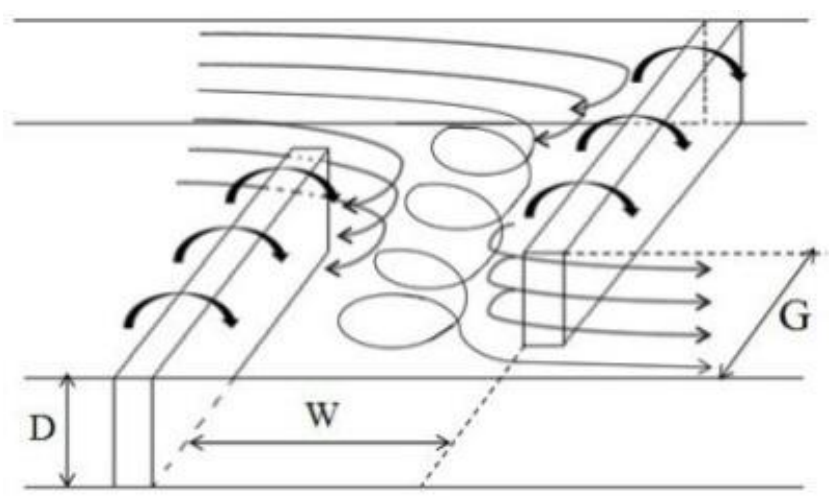

(b)

Fig. 2 
Set 1 No slot

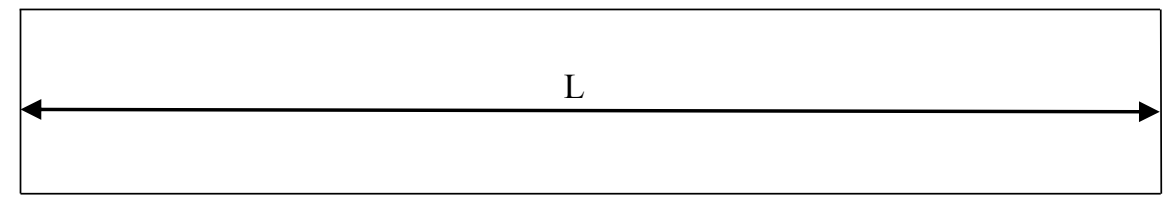

Set 2 One slot

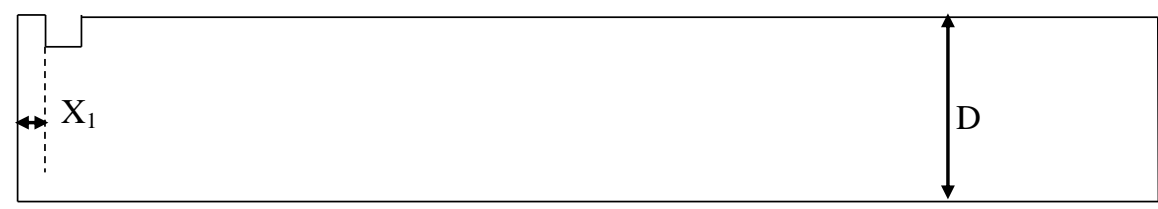

Set 3 Two slots
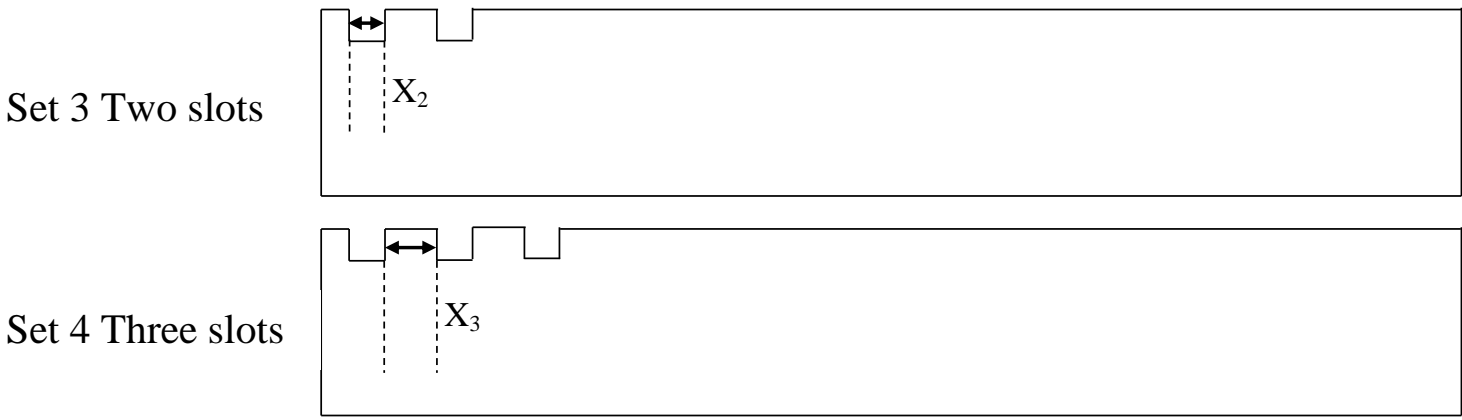

Set 5 Four slots

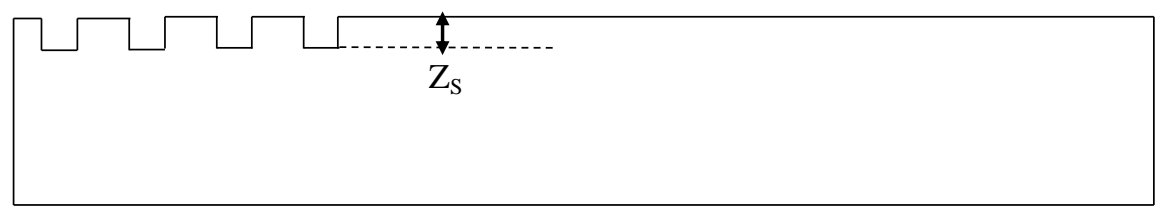

Fig. 3 


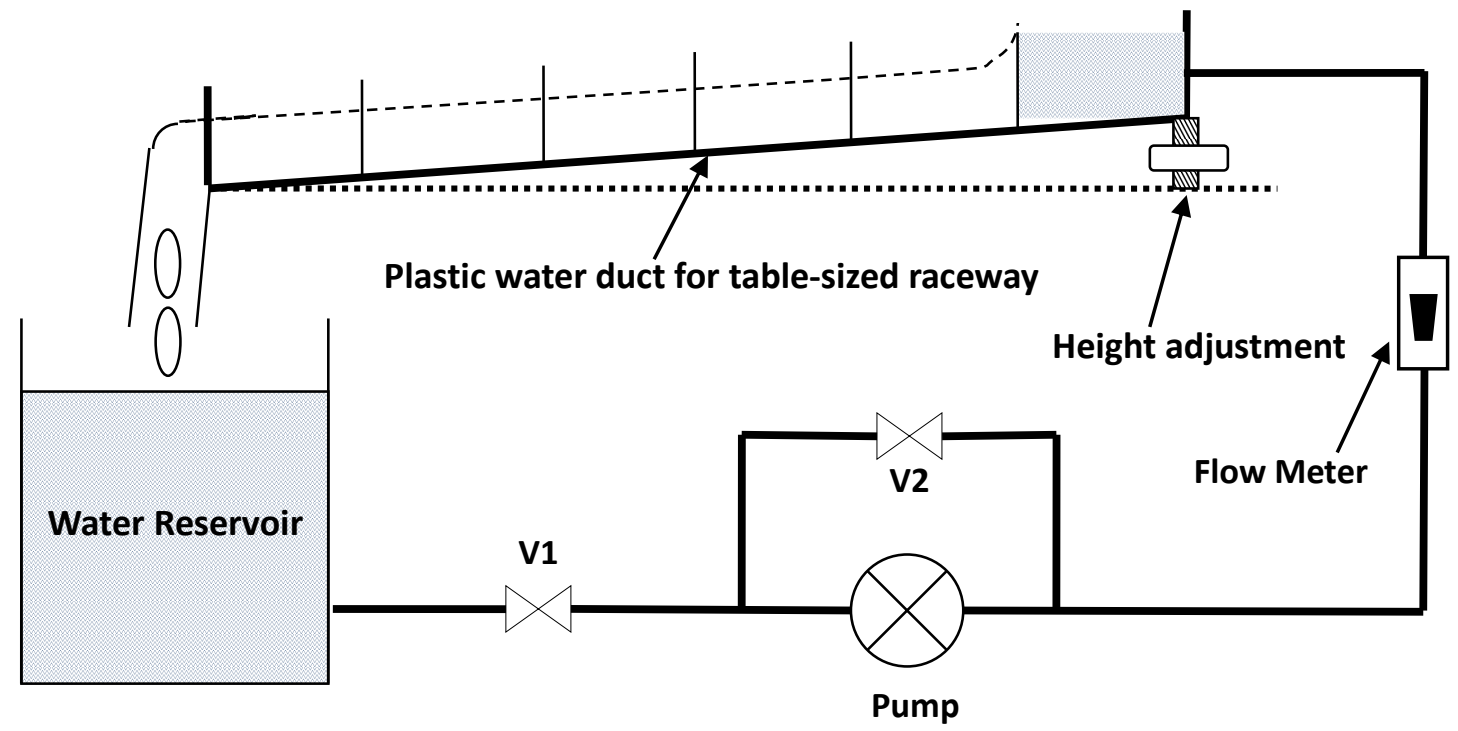

Fig. 4 


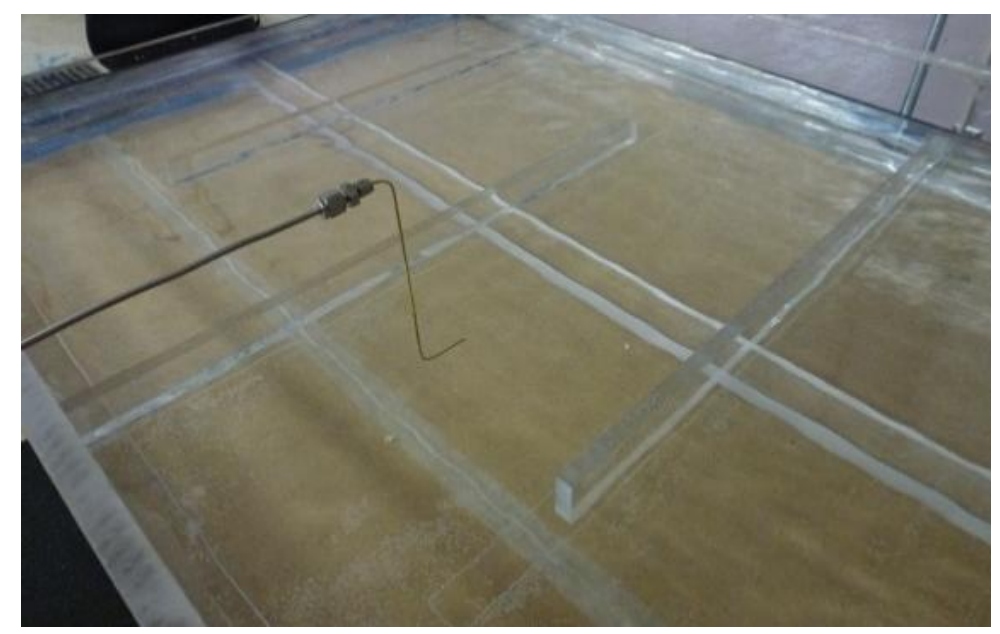

(a)

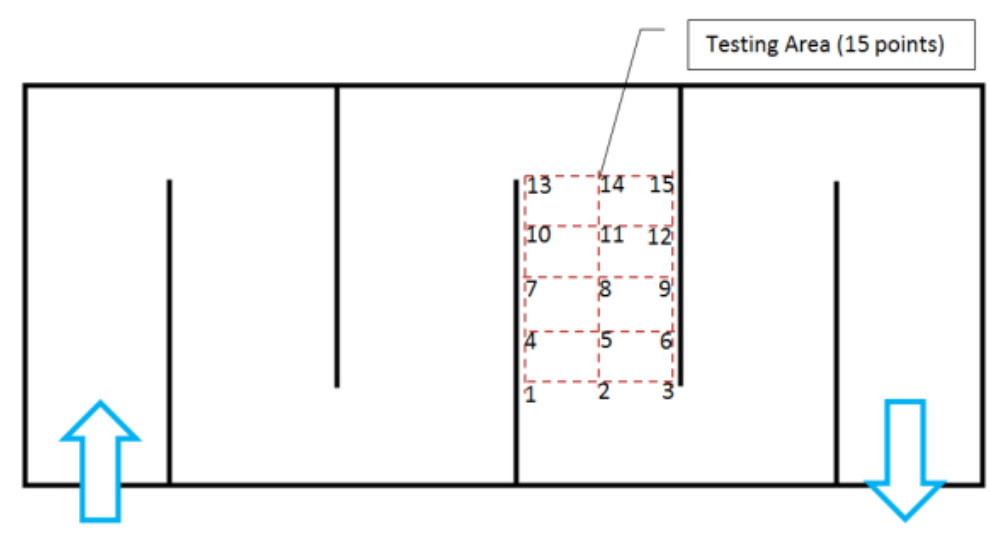

(b)

Fig. 5 


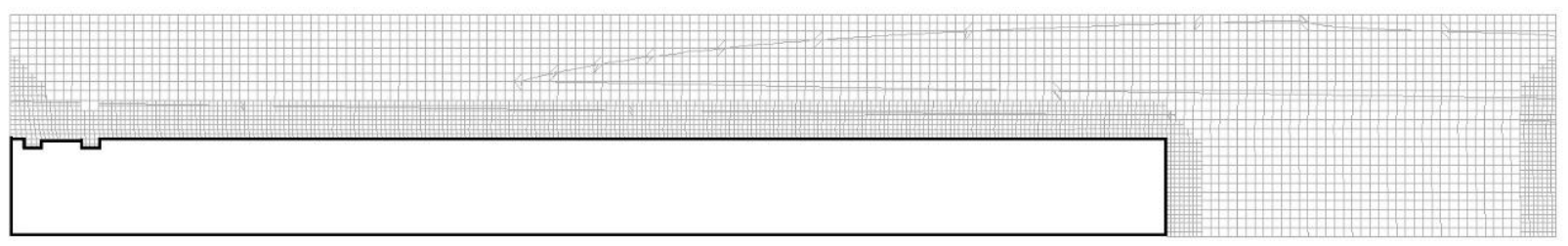

Fig. 6 


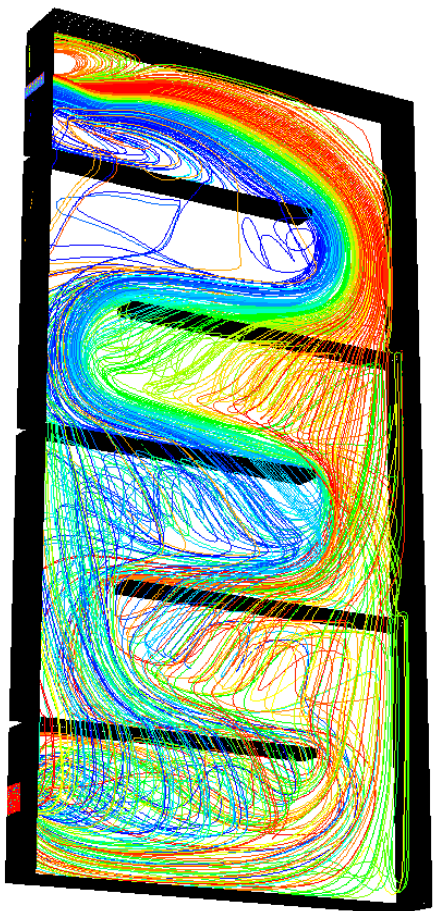

(a) Set 1

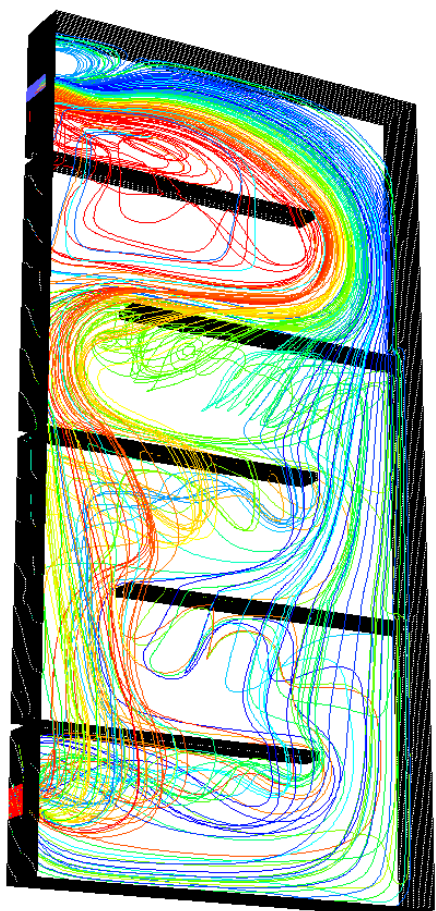

(b) Set 2

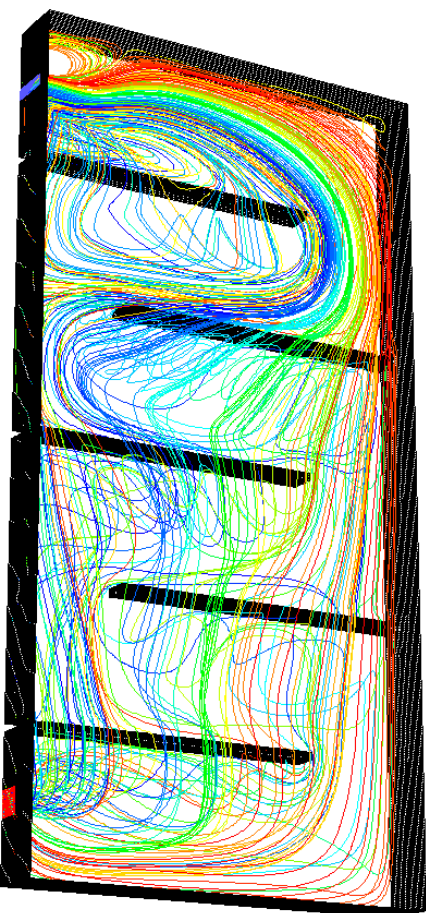

(c) Set 3

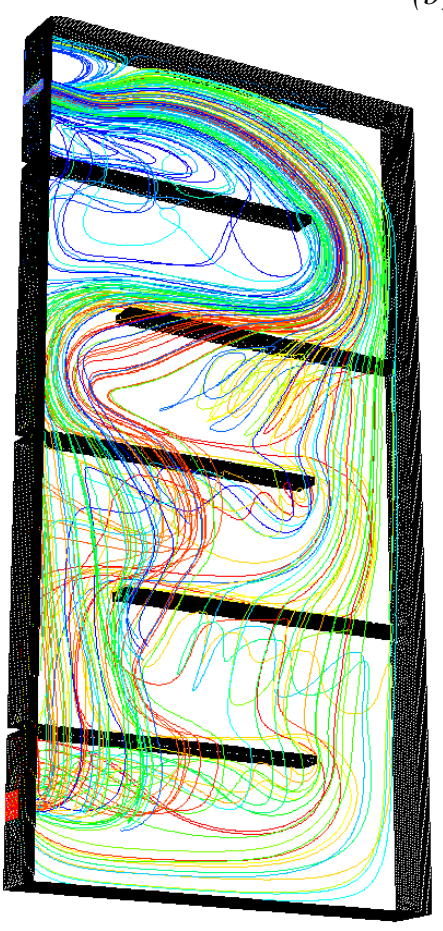

(d) Set 4

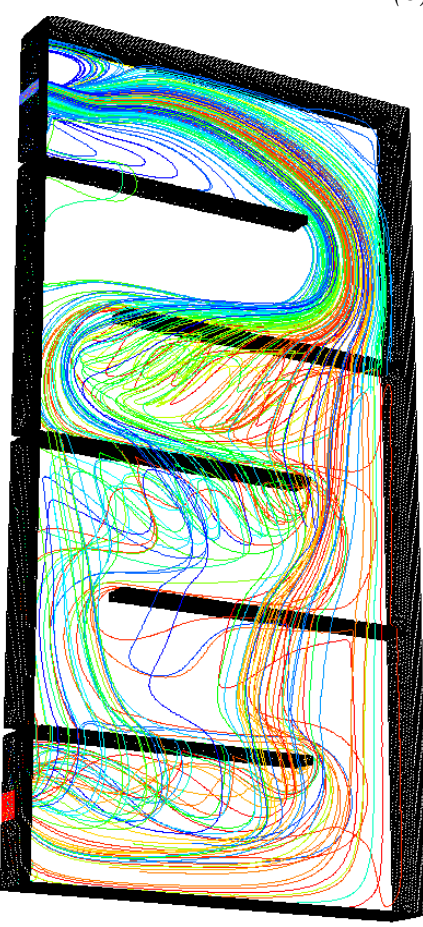

(e) Set 5

Fig. 7 


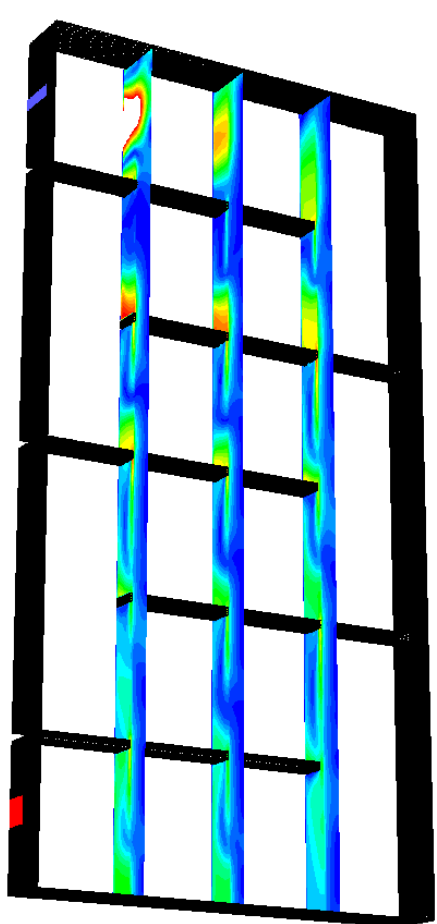

(a) Set 1

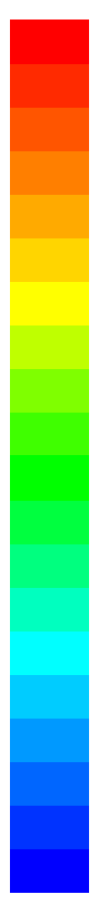

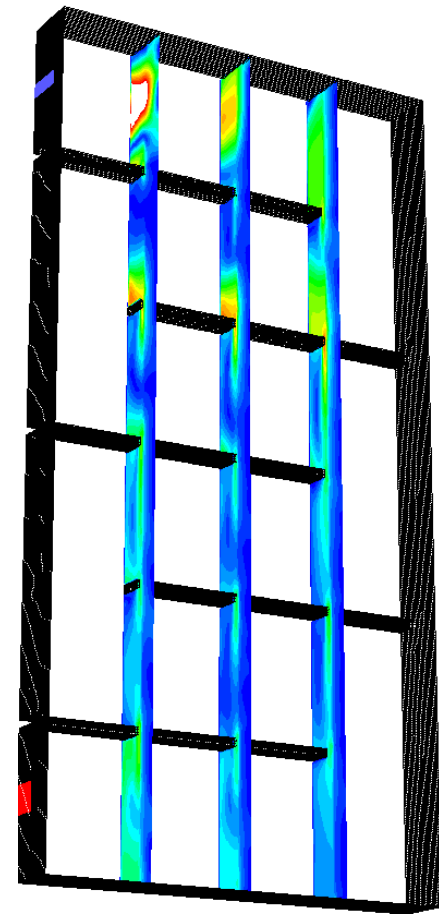

(b) Set 2

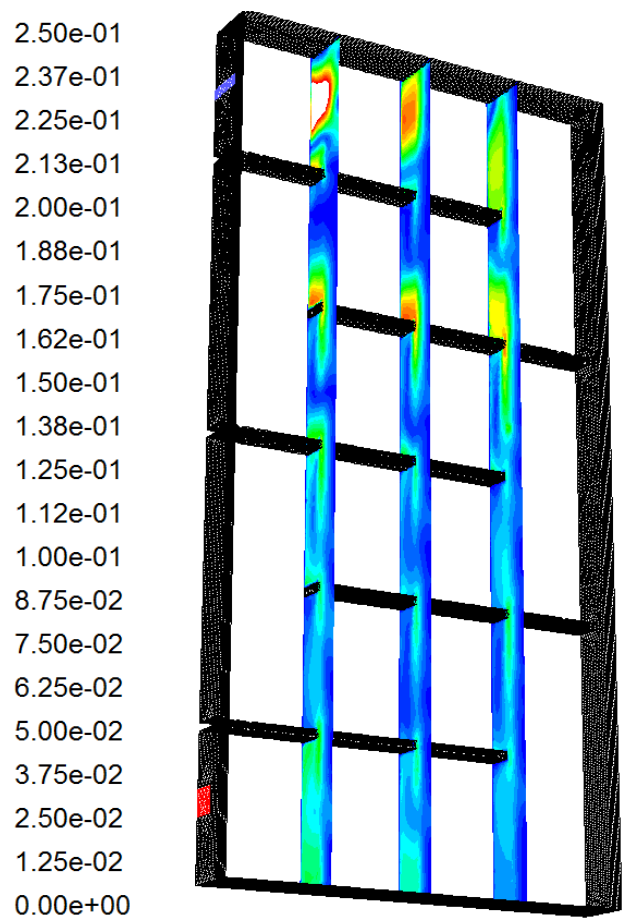

(d) Set 4

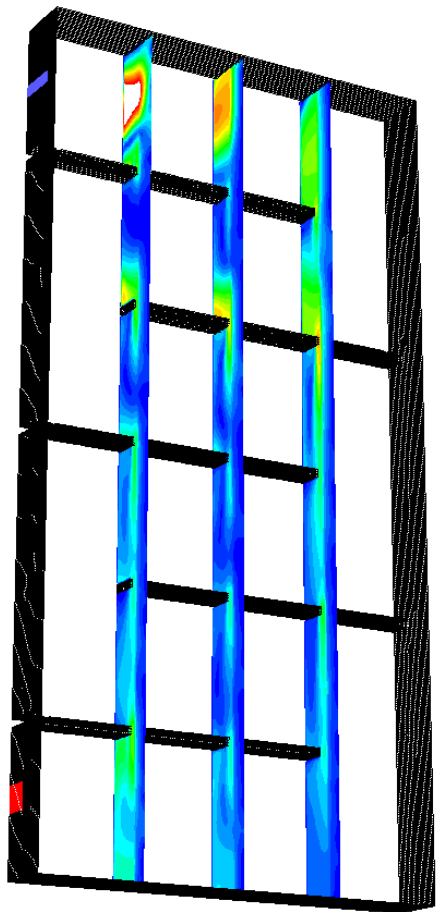

(c) Set 3

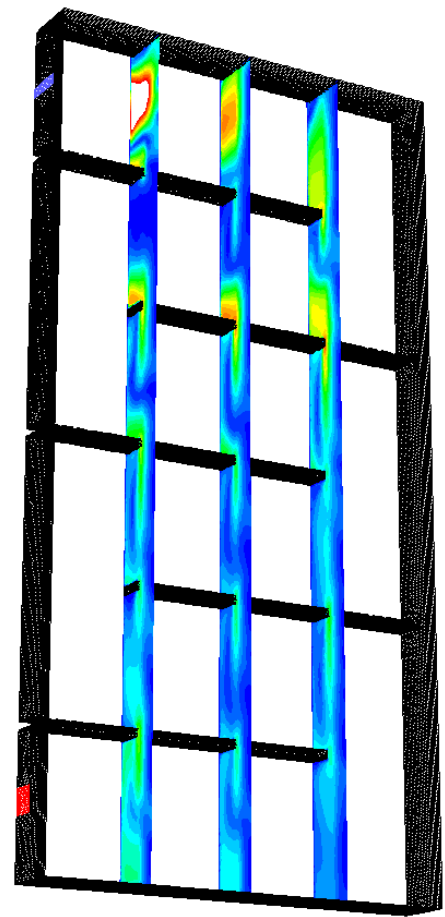

(e) Set 5

Fig. 8 


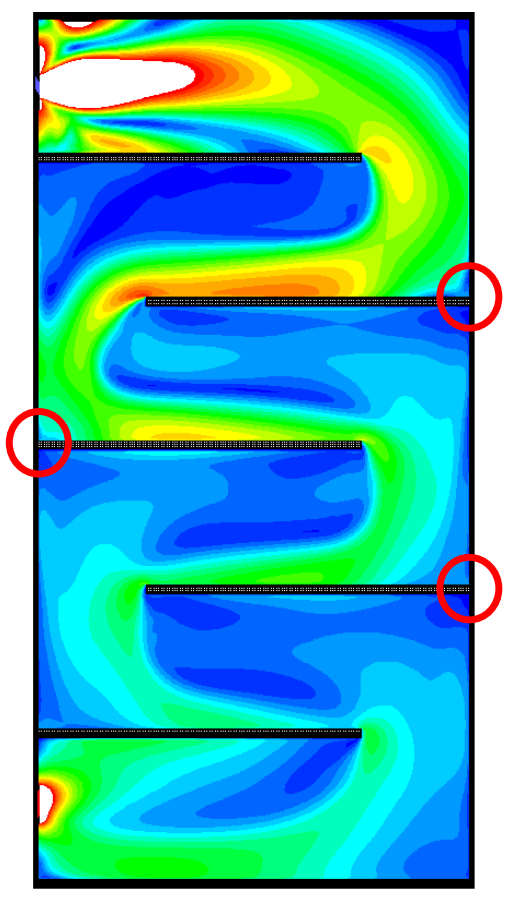

(a) Set 1

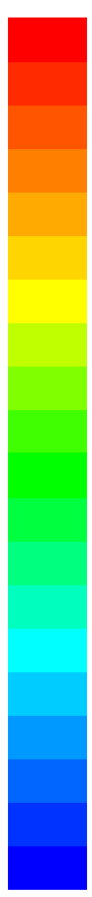

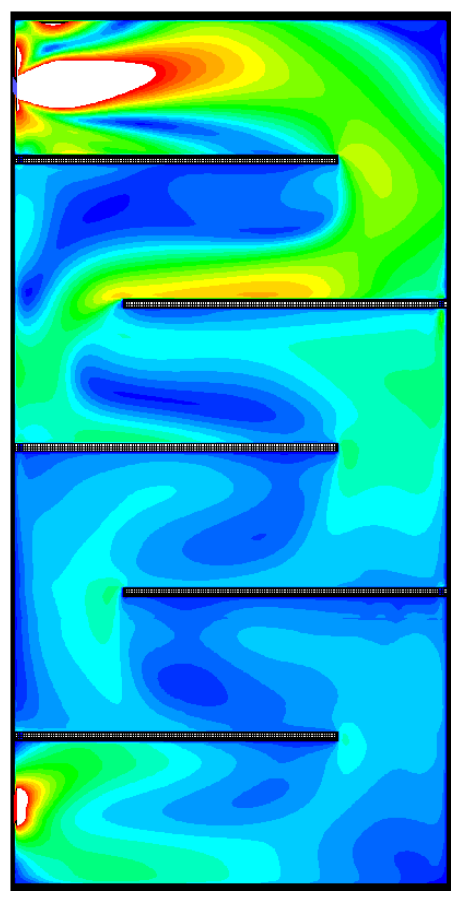

(b) Set 2

$2.50 \mathrm{e}-01$
$2.37 \mathrm{e}-01$
$2.25 \mathrm{e}-01$
$2.13 \mathrm{e}-01$
$2.00 \mathrm{e}-01$
$1.88 \mathrm{e}-01$
$1.75 \mathrm{e}-01$
$1.62 \mathrm{e}-01$
$1.50 \mathrm{e}-01$
$1.38 \mathrm{e}-01$
$1.25 \mathrm{e}-01$
$1.12 \mathrm{e}-01$
$1.00 \mathrm{e}-01$
$8.75 \mathrm{e}-02$
$7.50 \mathrm{e}-02$
$6.25 \mathrm{e}-02$
$5.00 \mathrm{e}-02$
$3.75 \mathrm{e}-02$
$2.50 \mathrm{e}-02$
$1.25 \mathrm{e}-02$
$0.00 \mathrm{e}+00$

$0.00 \mathrm{e}+00$

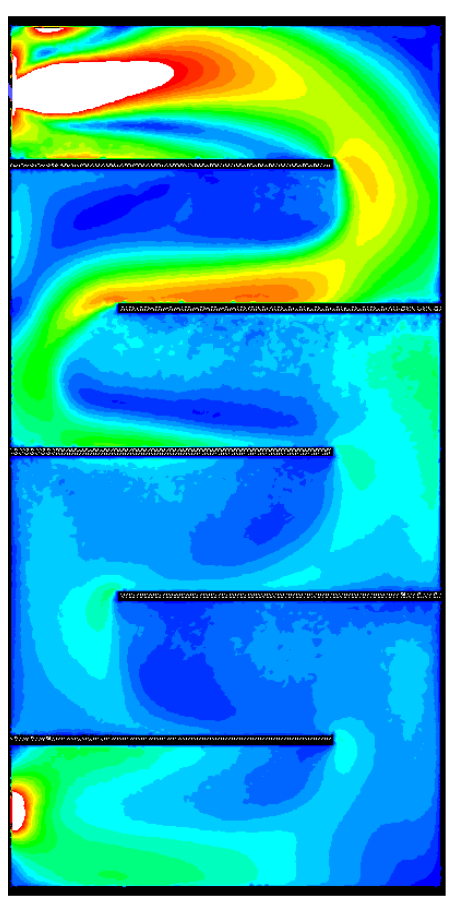

(d) Set 4

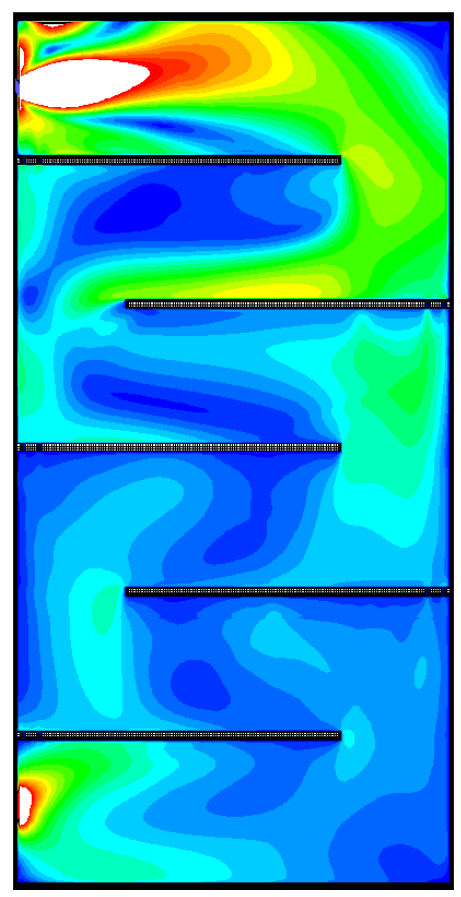

(c) Set 3

(e) Set 5

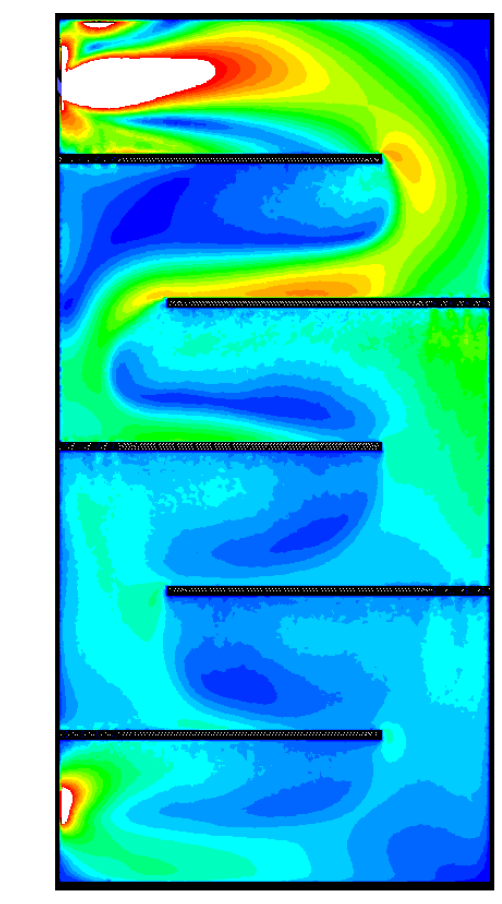

Fig. 9 


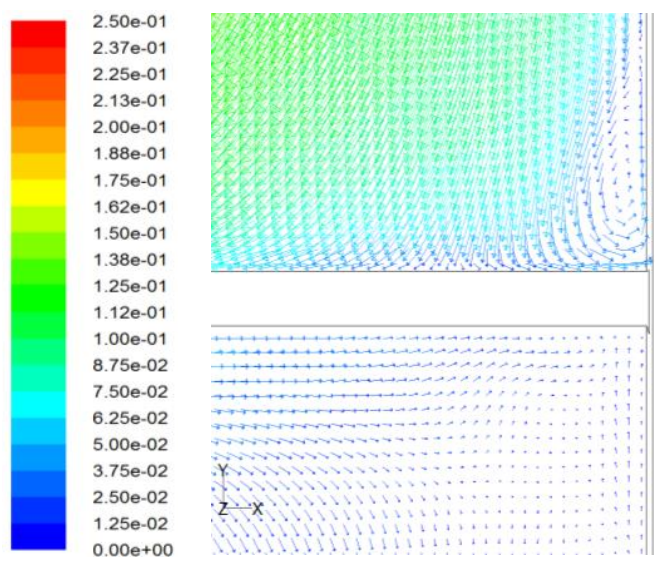

(a) No Slot

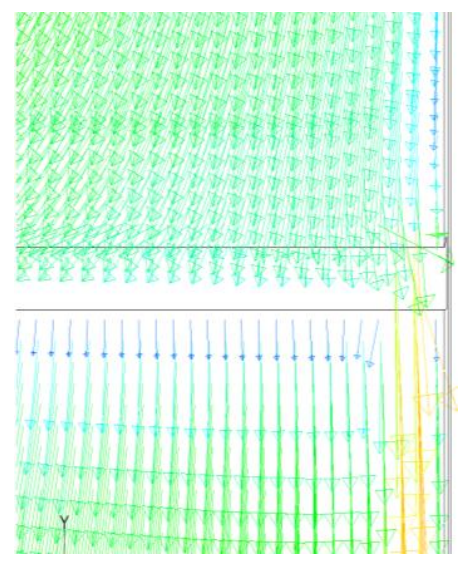

(b) One Slot

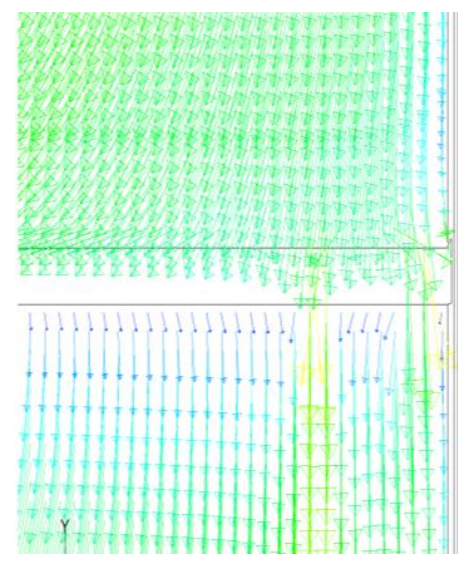

(c) Two Slots

Fig. 10 


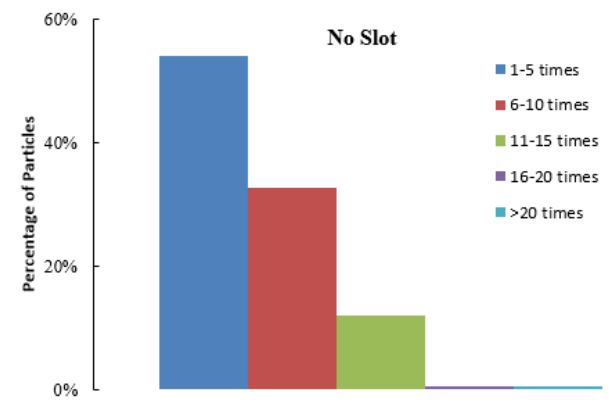

(a) Set 1

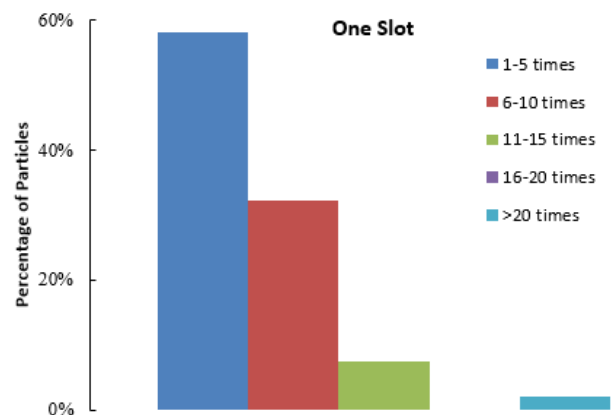

(b) Set 2
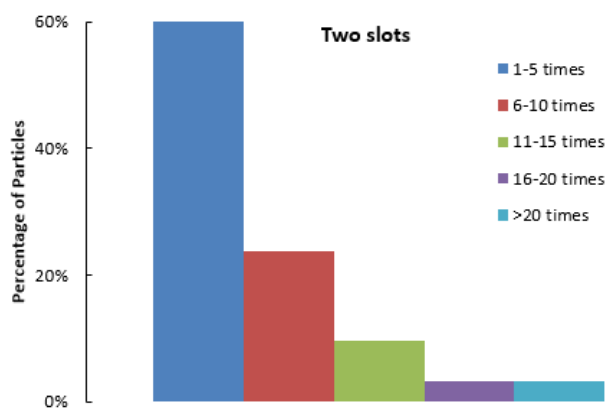

(c) Set 3
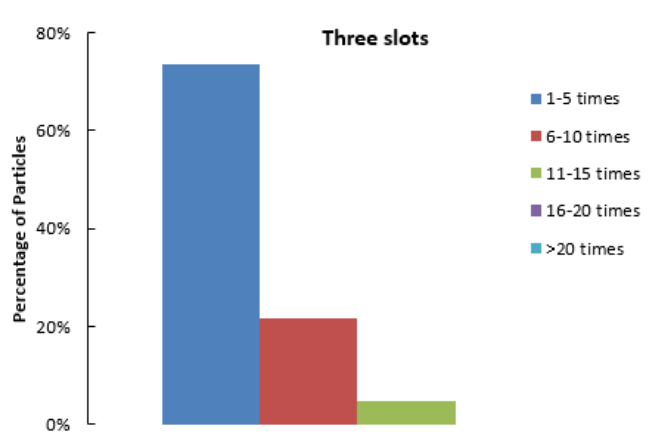

(d) Set 4
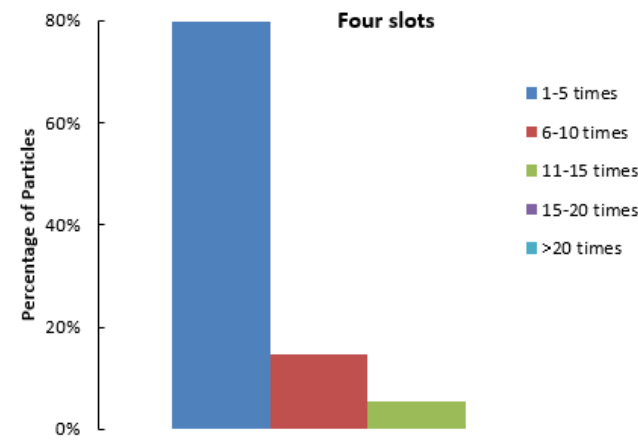

(e) Set 5

Fig. 11 


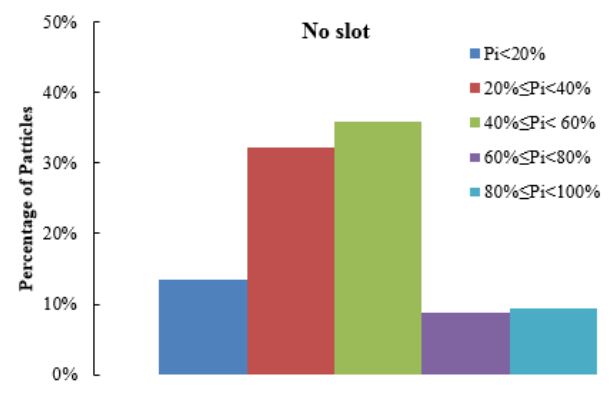

(a) Set 1

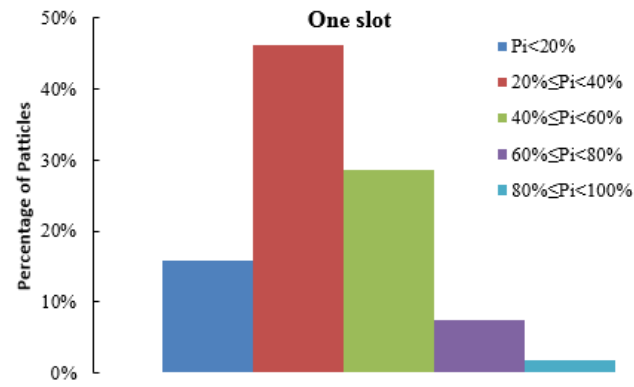

(b) Set 2

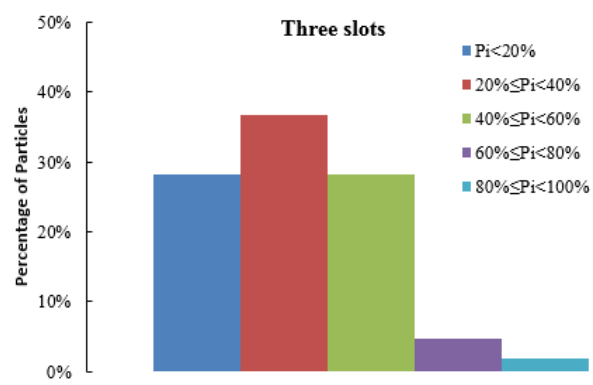

(d) Set 4

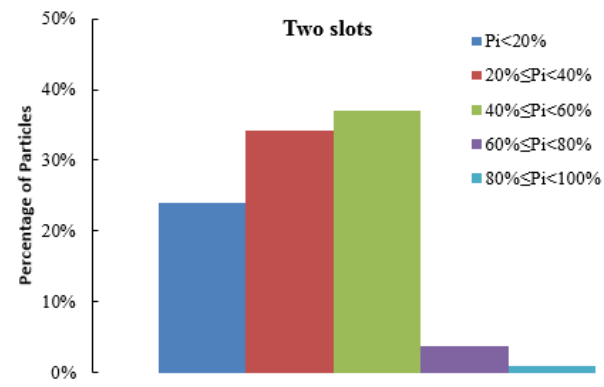

(c) Set 3

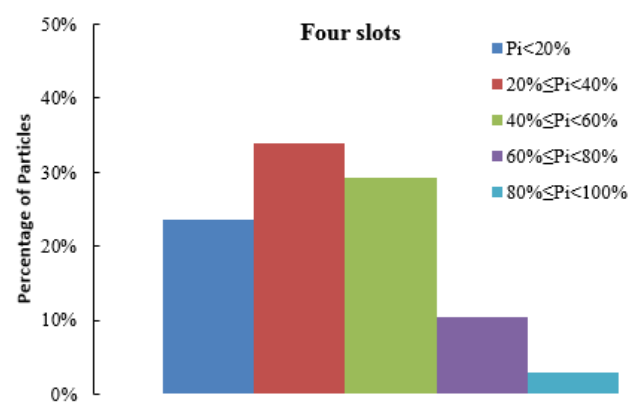

(e) Set 5

Fig. 12 


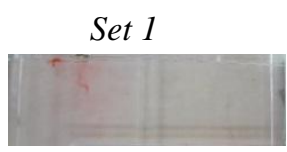

Set 2

Set 3

Set 4
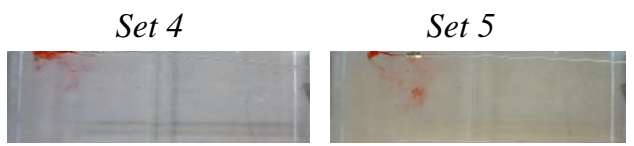

(Point 1)
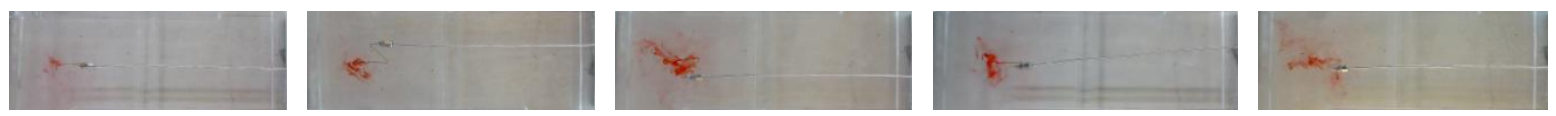

(Point 2)
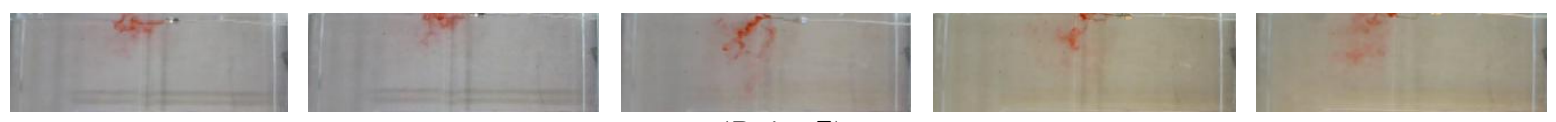

(Point 7)
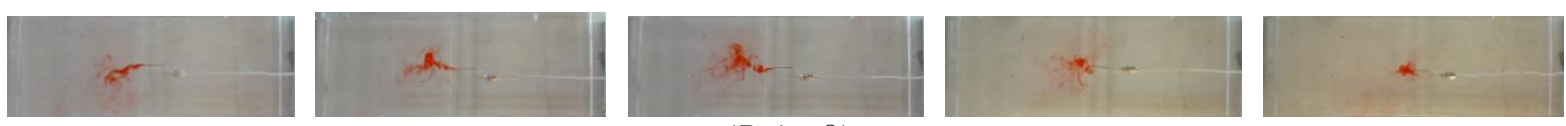

(Point 8)
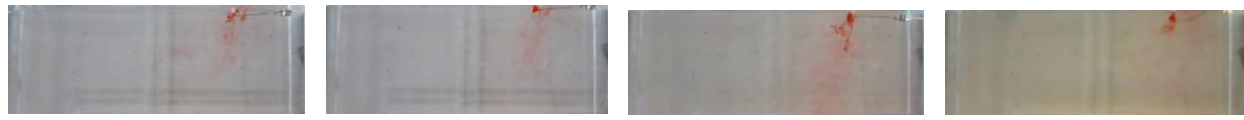

(Point 13)
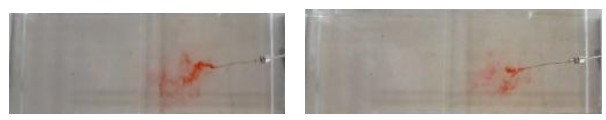

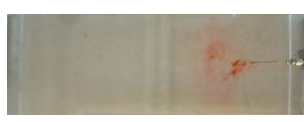

(Point 14)
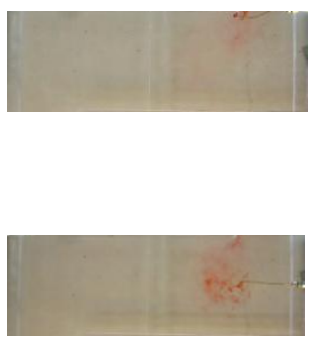

Fig. 13 


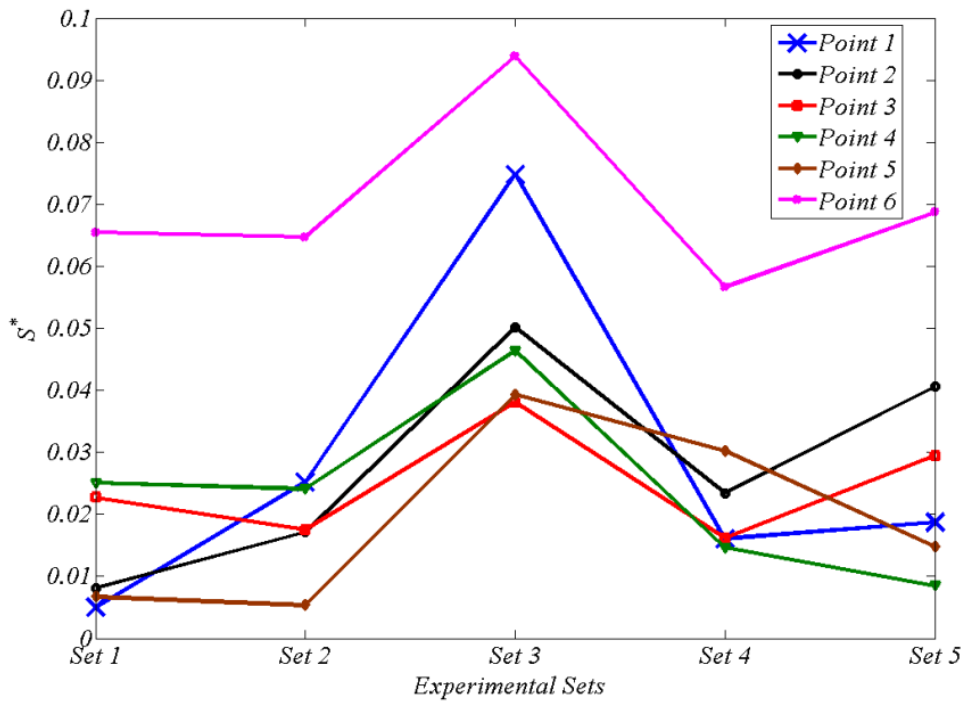

Fig. 14 